\title{
Effect of Ag Addition on the Gas-Sensing Properties of Nanostructured Resistive-Based Gas Sensors: An Overview
}

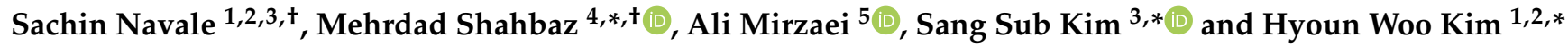 \\ 1 Division of Materials Science and Engineering, Hanyang University, Seoul 04763, Korea; \\ stnavale2@yahoo.com \\ 2 The Research Institute of Industrial Science, Hanyang University, Seoul 04763, Korea \\ 3 Department of Materials Science and Engineering, Inha University, Incheon 22212, Korea \\ 4 Department of Materials Science and Engineering, Faculty of Engineering, Urmia University, \\ Urmia 5756-151818, Iran \\ 5 Department of Materials Science and Engineering, Shiraz University of Technology, Shiraz 71557-13876, Iran; \\ mirzaei@sutech.ac.ir \\ * Correspondence: m.shahbaz@urmia.ac.ir (M.S.); sangsub@inha.ac.kr (S.S.K.); \\ Hyounwoo@hanyang.ac.kr (H.W.K.) \\ + These authors contributed equally to this work.
}

Citation: Navale, S.; Shahbaz, M.;

Mirzaei, A.; Kim, S.S.; Kim, H.W.

Effect of Ag Addition on the

Gas-Sensing Properties of

Nanostructured Resistive-Based Gas Sensors: An Overview. Sensors 2021,

21, 6454. https://doi.org/10.3390/

s21196454

Academic Editor: Chiman Kwan

Received: 3 September 2021

Accepted: 23 September 2021

Published: 27 September 2021

Publisher's Note: MDPI stays neutral with regard to jurisdictional claims in published maps and institutional affiliations.

Copyright: (c) 2021 by the authors. Licensee MDPI, Basel, Switzerland. This article is an open access article distributed under the terms and conditions of the Creative Commons Attribution (CC BY) license (https:// creativecommons.org/licenses/by/ $4.0 /)$.

\begin{abstract}
Nanostructured semiconducting metal oxides (SMOs) are among the most popular sensing materials for integration into resistive-type gas sensors owing to their low costs and high sensing performances. SMOs can be decorated or doped with noble metals to further enhance their gas sensing properties. Ag is one of the cheapest noble metals, and it is extensively used in the decoration or doping of SMOs to boost the overall gas-sensing performances of SMOs. In this review, we discussed the impact of Ag addition on the gas-sensing properties of nanostructured resistive-based gas sensors. Ag-decorated or -doped SMOs often exhibit better responsivities/selectivities at low sensing temperatures and shorter response times than those of their pristine counterparts. Herein, the focus was on the detection mechanism of SMO-based gas sensors in the presence of Ag. This review can provide insights for research on SMO-based gas sensors.
\end{abstract}

Keywords: Ag; decoration/loading; doping; gas sensor; sensing mechanism

\section{Semiconducting Metal Oxide (SMO)-Based Gas Sensors}

Toxic gases pose a major threat to modern life. Therefore, the early detection of toxic gases using reliable electronic gas sensors is extremely important. In this respect, chemiresistive gas sensors are potentially attractive due to their easy manufacturing, simple operating principle, and low cost [1-10]. In the area of resistive-based gas sensors, different semiconducting materials can be used for the realization of gas sensors. For example, the organic semiconducting materials such as organic $\pi$-conjugated materials have advantages of tailorable chemical structures, solution processability, and mechanical flexibility; thus, they are potential candidates for applications in low-cost, low-temperature, and portable gas sensors. Nonetheless, they have some shortages such as relatively poor sensitivity, slow response, and low recovery [1-3]. The functionalization of these materials with noble metals such as Ag through chemical methods can increase the response and selectivity to a particular gas; however, as far as we know, there is no or few studies in this regard. On the other hand, semiconducting metal oxides (SMO)-based gas sensors have advantages such as high response, high stability, relatively fast dynamics, simple fabrication, and low costs. So, they are very popular for the detection of various gases [4-14]. However, they work at high temperatures and show poor selectivity.

Typically, in the laboratory, gas-sensing measurements are dynamically conducted in an enclosed test chamber of a defined volume equipped with an inlet and outlet for gas flow [15]. Generally, ideal gas sensors must be inexpensive, operate at low temperatures 
or room temperature, detect gases at low levels, and be highly stable, sensitive, selective, and fast [16]. Nano-based gas-sensing materials possess high surface areas and unique electrical properties and consequently are preferred over their micron-sized counterparts for the development of gas sensors [17]. The detection mechanism of SMOs significantly depends on the modulation of electrical resistance due to the interaction of the sensing layer with the target gases [18]. The general sensing mechanism of resistive-based gas sensors is schematically shown in Figure 1 for n-type and p-type SMOs, in the presence of oxidizing and reducing gases. When an SMO is exposed to air, depending on the sensing temperature, the adsorption of oxygen on the sensor surface causes the ionization of oxygen molecules in the form of molecular or atomic ions. As a result of oxygen adsorption, a so-called electron depletion layer with a low concentration of electrons forms on the surfaces of n-type SMOs, which has a higher resistance than the core region of the metal oxide. Alternatively, a so-called hole accumulation layer forms on the surfaces of p-type SMOs, which has a lower resistance than the core regions of the metal oxides due to an increase in the number of holes as major carriers (Figure 1a). Upon exposure of the gas sensor to reducing gases, the gases will be adsorbed on the surface of the sensing layer and react with the already adsorbed oxygen ions, liberating the electrons back to the surface of the gas sensor. Thus, the width of the electron depletion layer in n-type metal oxides decreases, leading to a decrease in the resistance of the sensor. For p-type metal oxides, the width of the hole accumulation layer decreases because of the combination of the released electrons with holes, resulting in an increase in sensor resistance, which contributes to the sensor signal (Figure 1b). For oxidizing gases due to the further abstraction of electrons, the widths of both the electron depletion layer and hole accumulation layer increase, leading to an increase in resistance in n-type metal oxides and decrease in the resistance in p-type metal oxides (Figure 1c) [19,20].

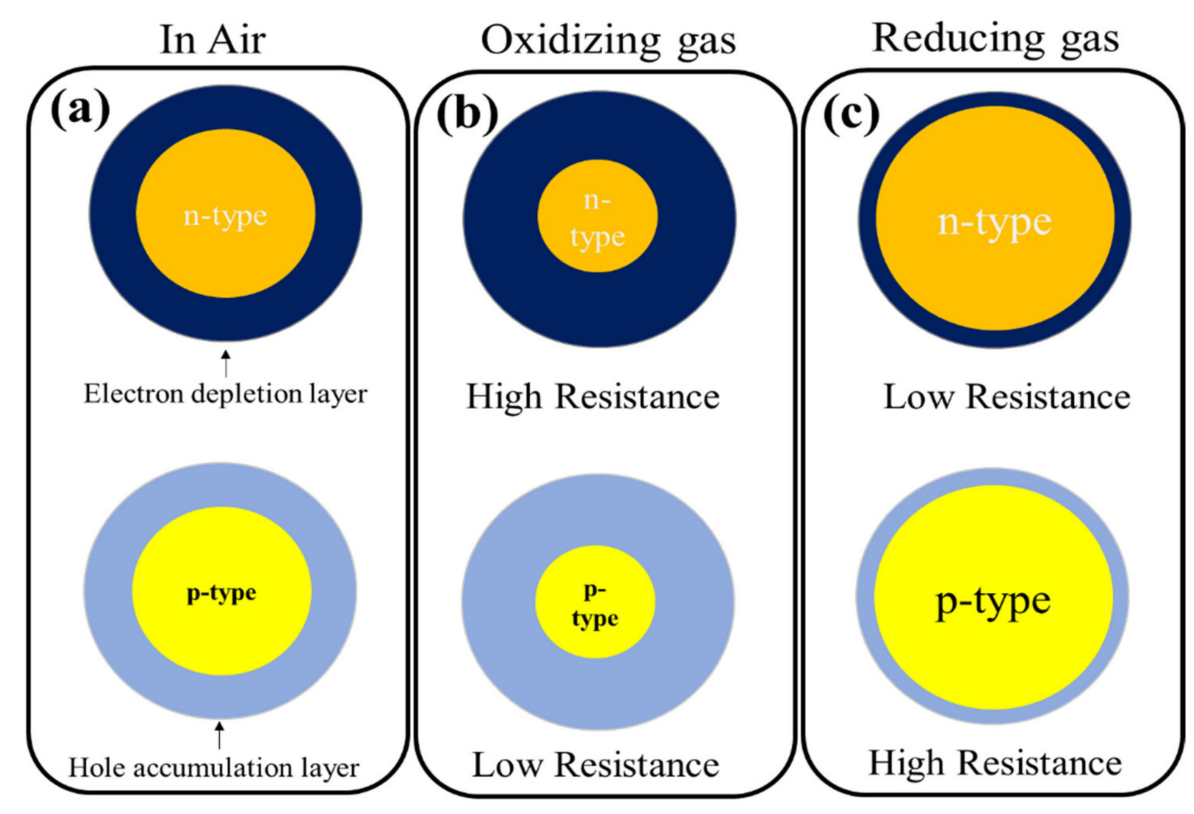

Figure 1. General gas-sensing mechanism of SMO-based gas sensors (a) n- and p-type SMO in air (b) in oxidizing gas atmosphere and (c) in reducing gas atmosphere $[19,20]$.

Since the adsorption of gas molecules on the surface of the gas sensor depends on the surface area, different morphologies have been investigated for gas-sensing applications. In fact, the larger surface area results in more availability of the adsorption sites on the surface of the gas sensor, resulting in a higher response of the gas sensor [21]. In addition to the increase in the surface area, several strategies, such as doping [22], decoration of noble metals [23], and formation of heterojunctions [24] have been reported to enhance the gas-sensing performances of SMOs. Selectivity is a challenging issue of resistive- 
based gas sensors and is not completely solved for gas sensors. However, there are some strategies to increase the selectivity of the gas sensor to a particular gas. For example, the control of sensing temperature, use of membranes, use of catalytic materials, and noble metal decoration have been suggested to increase the selectivity of resistive-based gas sensors [25].

\section{Noble Metal Decoration}

In the area of SMOs-based gas sensors, there are many review papers [26-35]. However, less attention has been paid to review the effect of noble metals on the gas-sensing performance of SMO-based gas sensors. Mirzaei et al. [36], Korotcenkov et al. [37], and Luo et al. [38] have discussed the effect of $\mathrm{Pd}, \mathrm{Au}$, and metal doping, respectively, on the gas response of SMO-based gas sensors. Mirzaei et al. [23] briefly discussed the effect noble metals on the gas response of SMO-based gas sensors. So, as far as we know, there is no review paper devoted solely to the effect of the addition of $\mathrm{Ag}$ in the form of decoration and doping on the gas response characteristics of SMO-based gas sensors. Thus, in this review paper, we have tried to cover this area of SMO-based gas sensors. It should be noted that in this manuscript, both decoration and loading are interchangeable words, and both of them mean the dispersion of Ag NPs on the surface of SMO.

Among the various strategies, the decoration of SMOs with noble metals is perhaps the most attractive strategy, and enhanced gas responses of the resulting sensors are mainly attributed to the chemical and electronic sensitization effects of noble metals [23,39]. Typically, noble metals are recognized for their catalytic activities, and they can decrease the adsorption activation energies of gases on the surfaces of SMOs and enhance the sensing activities of SMO-based sensors. The surface doping of noble metals may generate active surface sites that facilitate the preferred adsorption of target gases and increase their concentration. Moreover, noble metals can offer reaction paths that can reduce the activation energy and then improve the reaction rate and selectivity, sensitivity or response, and reliability of the sensor [22,23]. Generally, the chemical sensitization effect originates from a spillover effect, where the noble metal may act as a potential site for the adsorption and dissociation of $\mathrm{O}_{2}$ molecules [40]. Subsequent spillover onto neighboring SMOs results in enhancement of the adsorption rate of $\mathrm{O}_{2}$. Additionally, noble metals may catalyze the dissociation of target gases and boost the rates of reactions between the target gases and the previously chemisorbed $\mathrm{O}_{2}$ species. Basically, the chemical sensitization effect particularly depends on the operating temperature at which the catalytic pathway is preferred and is definite to the case where chemical affinities exist among the species concerned. However, the electronic sensitization effect arises from the direct electronic interaction between the promoter and the semiconductor surface. Typically, the electronic sensitization effect depends on the presence of a junction potential barrier between the semiconductor and the noble metal. Differences between the Fermi levels of the SMO and the catalyst cause the depletion or accumulation of charge carriers at the semiconductor, adjacent to the particles, because of the pinning effect [41-43]. When the oxidation state of a noble metal, including Ag, changes with respect to the surrounding atmosphere, the electronic state of the semiconductor accordingly varies because $\mathrm{Ag}$ can form $\mathrm{Ag}_{2} \mathrm{O}$ or $\mathrm{AgO}$ in air, whereas $\mathrm{Ag}_{2} \mathrm{O}$ or $\mathrm{AgO}$ is simply reduced to metallic $\mathrm{Ag}$ when exposed to a reducing gas. In fact, $\mathrm{Ag}_{2} \mathrm{O}$ or $\mathrm{AgO}$ create an electron-depletion layers within the semiconductor, whereas the electronic interaction is disrupted when $\mathrm{Ag}_{2} \mathrm{O}$ or $\mathrm{AgO}$ is reduced to $\mathrm{Ag}$ [41-43]. As an example, a schematic of the chemical and electronic sensitization effect of noble metals and SMOs (such as $\mathrm{TiO}_{2}$ ) with $\mathrm{H}_{2}$ gas as the target gas is shown in Figure 2 [22,42].

In this case, the $\mathrm{H}_{2}$ molecules may dissociate into $\mathrm{H}$ atoms on noble metal clusters and then spillover onto the $\mathrm{TiO}_{2}$ surface, which accelerates the reaction [22,39,42]. Herein, the noble metal clusters simply reduce the activation energy of the reaction or increase the reaction rate. The electronic sensitization effect can be attributed to electronic interactions between $\mathrm{TiO}_{2}$ and noble metal clusters. Accordingly, because of the difference between the work functions and electron affinities of $\mathrm{TiO}_{2}$ and noble metal, a depleted space 
charge region is generated close to the noble metal/ $\mathrm{TiO}_{2}$ interface, which causes band bending $[23,39]$. The electronic sensitization effect is primarily controlled by the spillover effect of $\mathrm{H}_{2}$ on the $\mathrm{TiO}_{2}$ surface and reduces the $\mathrm{TiO}_{2}$ resistance via the transfer of electrons at the noble metal $/ \mathrm{TiO}_{2}$ interface. In another case of doping, the dopant atoms enter the $\mathrm{TiO}_{2}$ framework and subsequently distort the $\mathrm{TiO}_{2}$ lattice, thereby producing many oxygen defects that provide higher local electric fields and facilitate the dissociation of $\mathrm{H}_{2}$ [22]. Consequently, the rate of the reaction between $\mathrm{H}$ and chemisorbed oxygen ions is enhanced, thereby reducing the response time. Additionally, more oxygen species may adsorb around the doped atoms than those in the case of pristine $\mathrm{TiO}_{2}$, thereby increasing the resistance and sensitivity or response of the sensor [23,39,41,42].

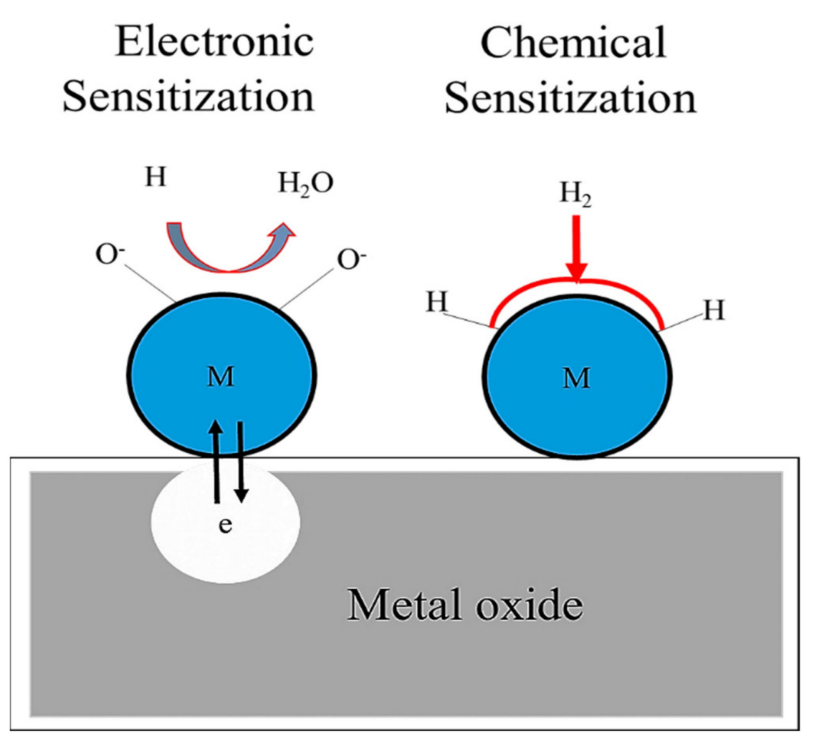

Figure 2. Schematic of chemical and electronic sensitizations in noble metal-decorated SMOs (in the figure, $\mathrm{M}=$ Metal, $\mathrm{e}=$ electron, $\mathrm{O}^{-}=$adsorbed oxygen) [22,31].

Generally, noble metals are very expensive. If even small amounts of noble metals are used for decorating or doping SMOs, the overall cost of the sensor inevitably increases. Nevertheless, among various noble metals such as $\mathrm{Pd}, \mathrm{Pt}$, and $\mathrm{Au}, \mathrm{Ag}$ has the lowest price. Furthermore, Ag has several interesting properties, for example, high efficiency and high reactivity toward $\mathrm{O}_{2}$ adsorption. Additionally, the Ag ion has been reported as a high mobility cation, which has been utilized in resistive-switching devices [43,44]. Moreover, Ag catalysts are efficient for not only improving the sensitivity of the sensor but also for reducing the working temperature owing to the unique catalytic and electronic characteristics of Ag. As an effective catalyst, Ag can attract $\mathrm{O}_{2}$ molecules in the air, transfer them to the surfaces of SMOs, and subsequently promote the capture of electrons from the conduction band of SMOs by these $\mathrm{O}_{2}$ molecules [41-44]. Therefore, $\mathrm{Ag}$ can be an appropriate sensitizer for introduction into the surfaces of SMO-based resistive gas sensors. Although the addition of Ag may boost the performance of the sensing material, a reasonable doping level/concentration of $\mathrm{Ag}$ is needed to realize the maximum sensing response. Typically, the decoration of SMO with $\mathrm{Ag}$ at an optimal concentration can result in the highest sensing performance of SMO. In fact, as the catalytic and electronic effects of $\mathrm{Ag}$ are unsatisfactory, the best sensing properties cannot be achieved when the loading amount of Ag is extremely low. When the loading or decoration concentration of Ag is substantially high, the electrons are conducted along metallic Ag, thereby decreasing the response of the gas sensor [45]. Generally, the best outcomes are obtained using ultrafine Ag nanoparticles (NPs) at low concentrations (0.1-10 wt.\%) and high surface dispersion, promoting the catalytic activity of the sensor without compromising the function of the sensing layer [46]. In the following section, we discuss some of the most recent and 
important studies on the application of Ag-decorated/loaded semiconductors for the detection of toxic and hazardous gases.

\section{Ag-Decorated/Loaded Gas Sensors}

\subsection{Ag-Decorated/Loaded Acetone $\left(\mathrm{CH}_{3} \mathrm{COCH}_{3}\right)$ Gas Sensors}

$\mathrm{CH}_{3} \mathrm{COCH}_{3}$ belongs to the family of volatile organic compounds (VOCs) that are employed as solvents in various industries. $\mathrm{CH}_{3} \mathrm{COCH}_{3}$ at higher levels may have a negative impact on the central nervous system and may be harmful to the eyes and nose. Therefore, the occupational threshold limit value for $\mathrm{CH}_{3} \mathrm{COCH}_{3}$ was set at $250 \mathrm{ppm}$ considering a timeweighted average of $8 \mathrm{~h}$ [47]. Accordingly, the development of sensitive $\mathrm{CH}_{3} \mathrm{COCH}_{3}$-sensing devices is required from the perspective of safety. In this regard, some attempts have been made to establish selective $\mathrm{CH}_{3} \mathrm{COCH}_{3}$ sensors by adding $\mathrm{Ag}$ into SMOs. For instance, $\mathrm{Xu}$ et al. [48] described the synthesis of Ag-decorated $\mathrm{SnO}_{2}$ hollow nanofibers (NFs) with large surface areas and their $\mathrm{CH}_{3} \mathrm{COCH}_{3}$ sensing properties. Typically, noble metals have higher electrical conductivities that enable the rapid transfer of electrons and catalysis of the oxidation of reducing gas molecules such as VOCs [45-48]. Thus, noble metal-incorporated sensing materials can be suitable candidates for detecting VOCs. The developed Ag-decorated $\mathrm{SnO}_{2}$ sensor showed an excellent response and higher selectivity for $\mathrm{CH}_{3} \mathrm{COCH}_{3}$ at $160^{\circ} \mathrm{C}$. A schematic of the sensing interactions between the $\mathrm{CH}_{3} \mathrm{COCH}_{3}$ gas molecules and pure and Ag-decorated $\mathrm{SnO}_{2}$ is shown in Figure 3. Owing to the presence of $p$-type $\mathrm{Ag}_{2} \mathrm{O}$ crystals, $\mathrm{p}$-n heterojunction interfaces formed between p-type $\mathrm{Ag}_{2} \mathrm{O}$ crystals and n-type $\mathrm{SnO}_{2}$, generating a broader depletion layer on the $\mathrm{SnO}_{2}$ side, thereby increasing the initial resistance of the sensing material. Upon exposure to $\mathrm{CH}_{3} \mathrm{COCH}_{3}$, significant modulation of the heterojunctions occurred and contributed to the sensor response. The $\mathrm{Ag}$ NPs produced $\mathrm{Ag}_{2} \mathrm{O}$ in air, which has facilitated the development of highly electron-depleted layers while removing electrons from $\mathrm{SnO}_{2}$. This process has increased the total resistance and the area adjacent to the $\mathrm{Ag}-\mathrm{SnO}_{2}$ interfaces, thus increasing the sensitivity of $\mathrm{SnO}_{2}$ to $\mathrm{CH}_{3} \mathrm{COCH}_{3}$. Furthermore, one-dimensional (1D) $\mathrm{SnO}_{2}$ hollow nanostructures fabricated via electrospinning considerably facilitated the diffusion and transport of electrons in $\mathrm{CH}_{3} \mathrm{COCH}_{3}$ molecules, thereby rapidly and substantially changing the sensor resistance. Additionally, $\mathrm{SnO}_{2}$ hollow NFs with both outer and inner surfaces exhibited high surface areas and eventually contributed to high $\mathrm{CH}_{3} \mathrm{COCH}_{3}$ responses. In summary, the significantly high $\mathrm{CH}_{3} \mathrm{COCH}_{3}$ sensing performances of $\mathrm{Ag} / \mathrm{SnO}_{2}$ composites are attributed to the $\mathrm{Ag}$ dopant and $1 \mathrm{D} \mathrm{NF}$ structures of $\mathrm{SnO}_{2}$. Ag with high electrical conductivity enabled the rapid transfer of electrons and catalyzed the oxidation of the reducing $\mathrm{CH}_{3} \mathrm{COCH}_{3}$ gas molecules. Moreover, the $\mathrm{SnO}_{2} \mathrm{NFs}$ with higher surface areas led to an effective dispersion of catalyst particles and possessed a porous tube-like structure that promoted rapid gas flow and a superior ability to store and release oxygen ions.

In another study, Kilic et al. [49] reported the $\mathrm{CH}_{3} \mathrm{COCH}_{3}$ sensing characteristics of $\mathrm{Ag}$ loaded $\mathrm{TiO}_{2}$ nanorods (NRs). They used a seed-mediated hydrothermal approach to grow $\mathrm{TiO}_{2} \mathrm{NRs}$ and subsequently loaded $\mathrm{Ag}$ onto $\mathrm{TiO}_{2} \mathrm{NRs}$ by thermally evaporating metallic $\mathrm{Ag}$ at different times of 30, 45, and $90 \mathrm{~s}$. The authors demonstrated that the enhancement in the $\mathrm{CH}_{3} \mathrm{COCH}_{3}$ detection performance of the Ag-loaded $\mathrm{TiO}_{2}(45 \mathrm{~s})$ sensor was due to the catalytic activity of Ag. Actually, Ag loading increased the number of adsorption sites on the surface of $\mathrm{TiO}_{2}$ and accelerated the rate of electron exchange between the $\mathrm{TiO}_{2}$ surface and $\mathrm{CH}_{3} \mathrm{COCH}_{3}$ molecules. Under a $\mathrm{CH}_{3} \mathrm{COCH}_{3}$ atmosphere, the bonds between $\mathrm{CH}_{3} \mathrm{COCH}_{3}$ molecules were easily dissociated by $\mathrm{Ag}$, allowing these molecules to quickly interact with the chemisorbed oxygen species. Moreover, the decoration of Ag NPs onto $\mathrm{TiO}_{2}$ NRs pinned the Fermi level of $\mathrm{TiO}_{2}$ because of the transfer of electrons from $\mathrm{TiO}_{2}$ to Ag. This led to surface band bending and induced a more pronounced electron-hole separation effect, thereby enhancing the sensitivity of the sensor to $\mathrm{CH}_{3} \mathrm{COCH}_{3}$. The lower $\mathrm{CH}_{3} \mathrm{COCH}_{3}$ response of the $\mathrm{Ag}$-loaded $\mathrm{TiO}_{2}(90 \mathrm{~s})$ sensor was associated with the accumulation of $\mathrm{Ag}$ clusters on the $\mathrm{TiO}_{2}$ surface, which impeded $\mathrm{O}_{2}$ diffusion within $\mathrm{TiO}_{2}$ and reduced the catalytic activity of $\mathrm{Ag}$. 


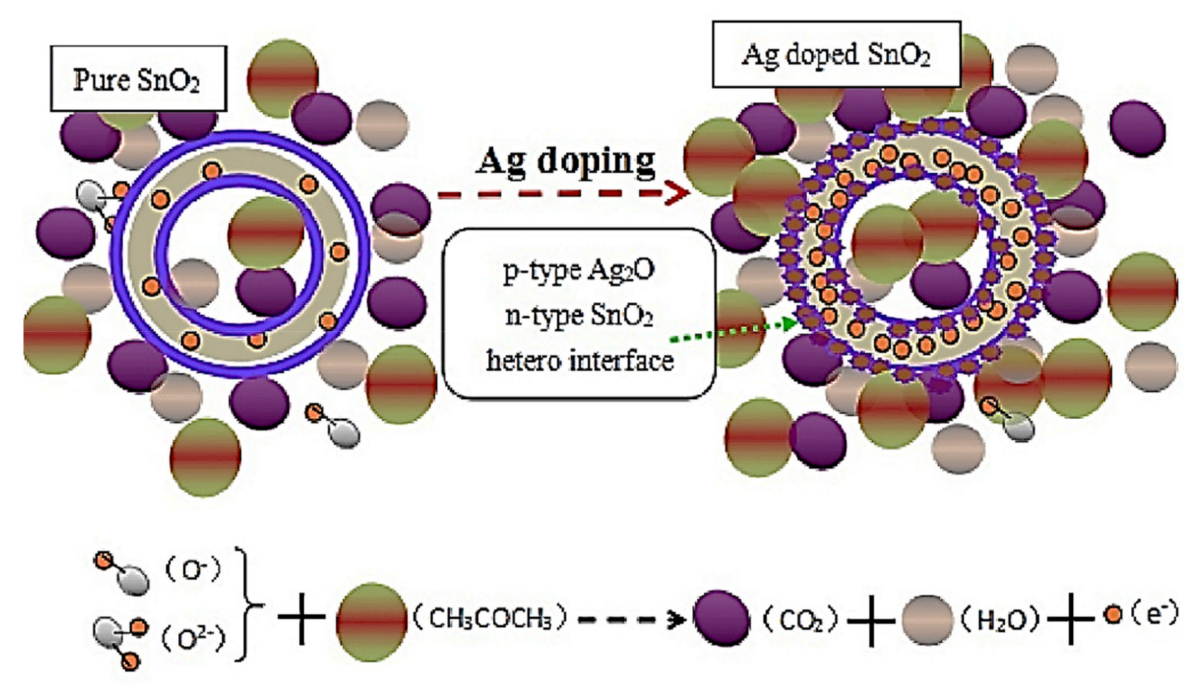

Figure 3. Schematic representing the $\mathrm{CH}_{3} \mathrm{COCH}_{3}$ sensing mechanism of pure and Ag-doped $\mathrm{SnO}_{2}$. Reprinted from reference [48] with permission from Elsevier.

\section{2. $\mathrm{Ag}$-Decorated/Loaded Chlorine $\left(\mathrm{Cl}_{2}\right)$ Gas Sensors}

$\mathrm{Cl}_{2}$ gas is very hazardous to the human respiratory mucous membrane at concentrations in the range $0.2-3.5 \mathrm{ppm}$. It causes psychological disorders, skin infections, and even liver damage. Hence, the early detection and successive monitoring of hazardous $\mathrm{Cl}_{2}$ by reliable gas sensors are highly important. Few studies have been reported on the $\mathrm{Cl}_{2}$ detection properties of Ag-loaded sensors. $\mathrm{Li}$ et al. [50] illustrated the effect of $\mathrm{Ag}$ loading on the $\mathrm{Cl}_{2}$ response of bismuth ferrite $\left(\mathrm{BiFeO}_{3}, \mathrm{BFO}\right)$ nanospheres (BFO NSs); they synthesized BFO NSs using a sol-gel route and successively loaded Ag NP onto BFO NSs via a photodeposition technique. Typically, BFO has a distinct surface reactivity, $\mathrm{O}_{2}$ adsorption ability, and a narrow band gap, which are beneficial for improving the gas-sensing characteristics. Therefore, BFO NSs are important candidates for the detection of $\mathrm{Cl}_{2}$. The observed response of the optimum $4 \mathrm{mg} \mathrm{AgNO}$-modified $\mathrm{BFO}$ sensor to 10 ppm $\mathrm{Cl}_{2}$ was 72.62 at a working temperature of $240{ }^{\circ} \mathrm{C}$. This response was 2.5 times that of the pure BFO sensor. A schematic of the energy band structure and hole transfer after the loading of Ag NPs is shown in Figure 4. Upon the loading of Ag NPs onto BFO, the positive charges on $\mathrm{BFO}$ reduced, and downward band bending occurred because the holes on the BFO NSs transferred to the Ag NPs. Along with the separation of electrons and holes, the electrons probably combined with $\mathrm{O}_{2}$ and $\mathrm{Cl}_{2}$ on the surface of the gas sensor. No barriers were formed because of the reduction in the number of conduction band electrons, thus supporting the progress of the reaction. Moreover, the Fermi levels of $\mathrm{Ag}$ and $\mathrm{BFO}$ correspond to one another at the same level, following contact because BFO $(\Phi \mathrm{m})$ has a lower work function than that of $\mathrm{Ag}(\Phi \mathrm{s})$. Here, Ag NPs might also be used as distinct adsorption sites for $\mathrm{O}_{2}$ and $\mathrm{Cl}_{2}$. Furthermore, at the $\mathrm{Ag} / \mathrm{BFO}$ interface, a Schottky junction was created that decreased the intergranular barriers and enhanced the interfacial effect [50].

In contrast, the number of electrons at the reaction sites increased, and the reaction quickly saturated because of the rapid transfer of charge carriers from $\mathrm{BFO}$ to $\mathrm{Ag}$. Consequently, the gas response significantly improved, and the response time shortened. However, the amount of adsorbed $\mathrm{O}$ ions decreased when high amounts of $\mathrm{Ag}$ were loaded onto the BFO NSs, which reduced the reactions of $\mathrm{O}_{2}$ and $\mathrm{Cl}_{2}$, thereby decreasing the sensor response. Thus, this study demonstrates that the addition of noble metals presents a new way of enhancing the sensitivity of p-type semiconductors toward $\mathrm{Cl}_{2}$ gas. 
(a)

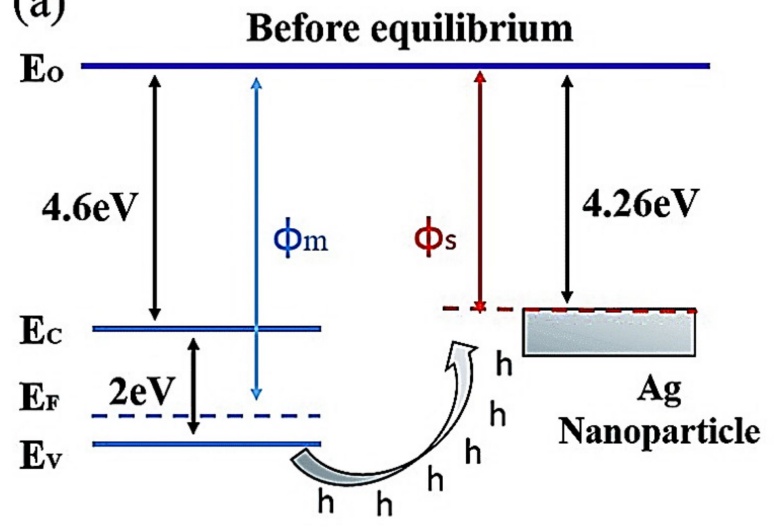

(b)

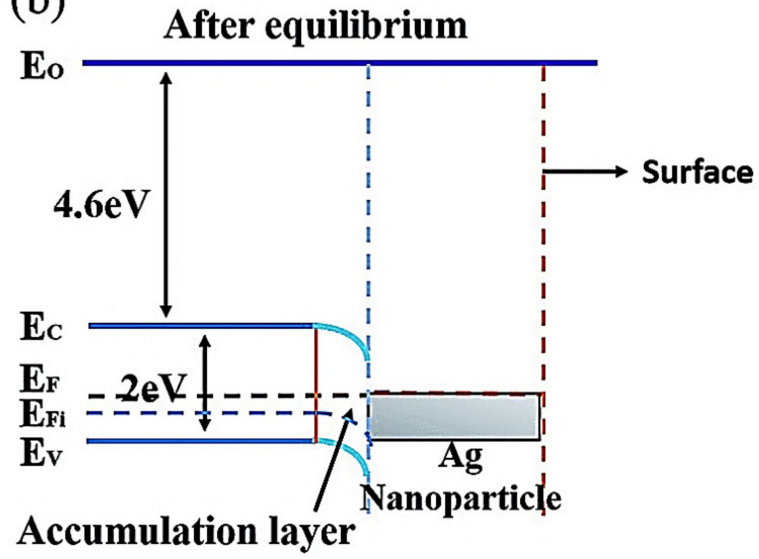

Figure 4. Energy band diagram and hole transfer in Ag NP-decorated BFO NSs (a) before and (b) after equilibrium [50]. Reproduced from https://pubs.rsc.org/en/content/articlelanding/2018/ra/c8ra06247a (accessed on 26 September 2018) from RSC. (This article is licensed under a Creative Commons Attribution-NonCommercial 3.0 Unported Licence).

\subsection{Ag-Decorated/Loaded Acetylene $\left(\mathrm{C}_{2} \mathrm{H}_{2}\right)$ Gas Sensors}

$\mathrm{C}_{2} \mathrm{H}_{2}$ is a flammable and colorless gas with a peculiar odor and is commonly utilized as a fuel in oxyacetylene welding and metal cutting and as a raw material in various industries. $\mathrm{C}_{2} \mathrm{H}_{2}$ poses serious threats due to its inherent instability, primarily in the cases of liquefaction, pressurization, heating, or mixing with air. This means that $\mathrm{C}_{2} \mathrm{H}_{2}$ can cause massive explosions if it leaks. Accordingly, from environmental and safety perspectives, the development of highly efficient $\mathrm{C}_{2} \mathrm{H}_{2}$ sensors is becoming increasingly important [31,51,52]. In this regard, Uddin et al. [51] described the $\mathrm{C}_{2} \mathrm{H}_{2}$ sensing properties of chemically synthesized 0-5 wt.\% Ag-loaded $\mathrm{ZnO}$-reduced graphene oxide (ZG-Ag) ternary hybrids. Generally, herein, the use of rGO was preferred over that of graphene because of difficulties in the large-scale production of graphene and lack of functional groups and band gaps in graphene [53]. Transmission electron microscopy (TEM) and high-resolution TEM (HRTEM) images (Figure 5) support the $\mathrm{Ag} / \mathrm{ZnO} / \mathrm{Gr}$ configuration of these heterostructures.

The Ag-loaded sensor based on ternary hybrids showed a higher response than that of the sensor without $\mathrm{Ag}$. The sensor without $\mathrm{Ag}$ could detect $16-100 \mathrm{ppm} \mathrm{C}_{2} \mathrm{H}_{2}$ at $250{ }^{\circ} \mathrm{C}$. The response of the $3 \mathrm{wt} . \%$ Ag-loaded $\mathrm{ZnO}-\mathrm{Gr}$ (ZG-Ag3) sensor was 22 at $150{ }^{\circ} \mathrm{C}$, indicating that $3 \mathrm{wt} . \%$ was the optimum loading amount of Ag. The loading of $3 \mathrm{wt} . \%$ Ag onto the $\mathrm{ZnO}-\mathrm{Gr}$ sensor not only enhanced the sensor response but also reduced the optimum sensing temperature. $\mathrm{Ag}$ has a superior capacity to dissociate $\mathrm{O}_{2}$ than $\mathrm{ZnO}$, and it catalyzes the dissociation of molecular $\mathrm{O}_{2}$ on the sensor surface, which generates higher $\mathrm{C}_{2} \mathrm{H}_{2}$-sensing active sites and thereby a higher sensor response. The development of depletion layers around the $\mathrm{ZnO}$ NPs due to the presence of $\mathrm{Ag}$ was mostly correlated with the modulation of nano-Schottky barriers, thereby improving the low-temperature surface reactivity. Upon the loading of $\mathrm{Ag}$ onto the $\mathrm{ZnO}-\mathrm{Gr}$ sensor, further dynamic sites generated at the sensing layer/Ag interfaces because of the spillover effect, and a larger number of $\mathrm{C}_{2} \mathrm{H}_{2}$ molecules adsorbed on the sensor surface. Therefore, a high sensor response was obtained when the loading amount of Ag was optimal. Nevertheless, when an excess amount of Ag was loaded, the $\mathrm{O}_{2}$ molecules dissociated on the surface and surpassed the percolation threshold, which caused an overlapping spillover zone, ultimately affecting the efficient transfer of $\mathrm{O}_{2}$ and decreasing the chances of $\mathrm{C}_{2} \mathrm{H}_{2}$ adsorption; this reduced the sensor response. 

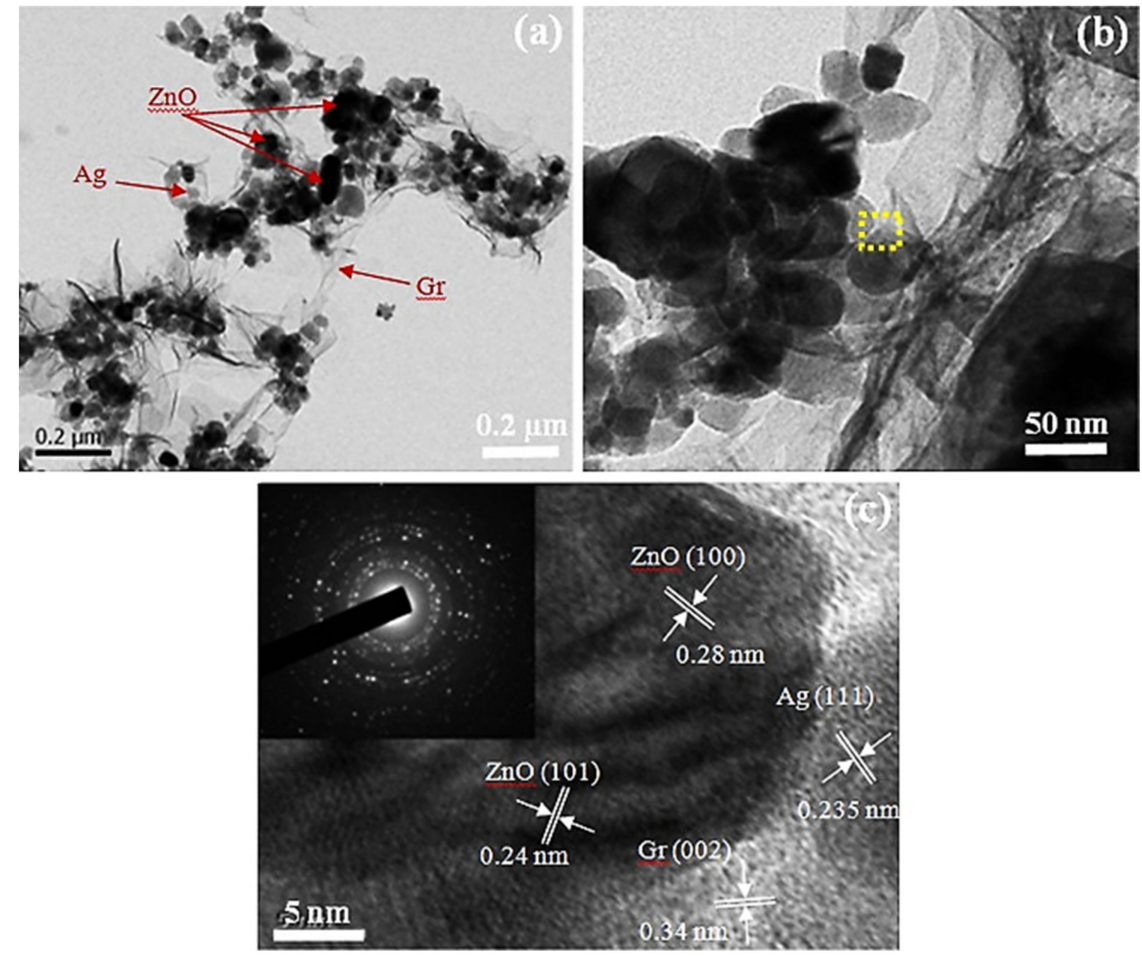

Figure 5. (a) TEM and (b,c) HRTEM images of the ZG-Ag3 hybrid (inset shows the equivalent SAED pattern). Reprinted from reference [51] with permission from Elsevier.

In another study associated with the detection of $\mathrm{C}_{2} \mathrm{H}_{2}$, Uddin et al. [54] designed a $\mathrm{C}_{2} \mathrm{H}_{2}$ sensor using Ag-decorated ZnO NRs supported by a flexible polyimide (PI)/polytetrafluoroethylene (PTFE) substrate (Figure 6).
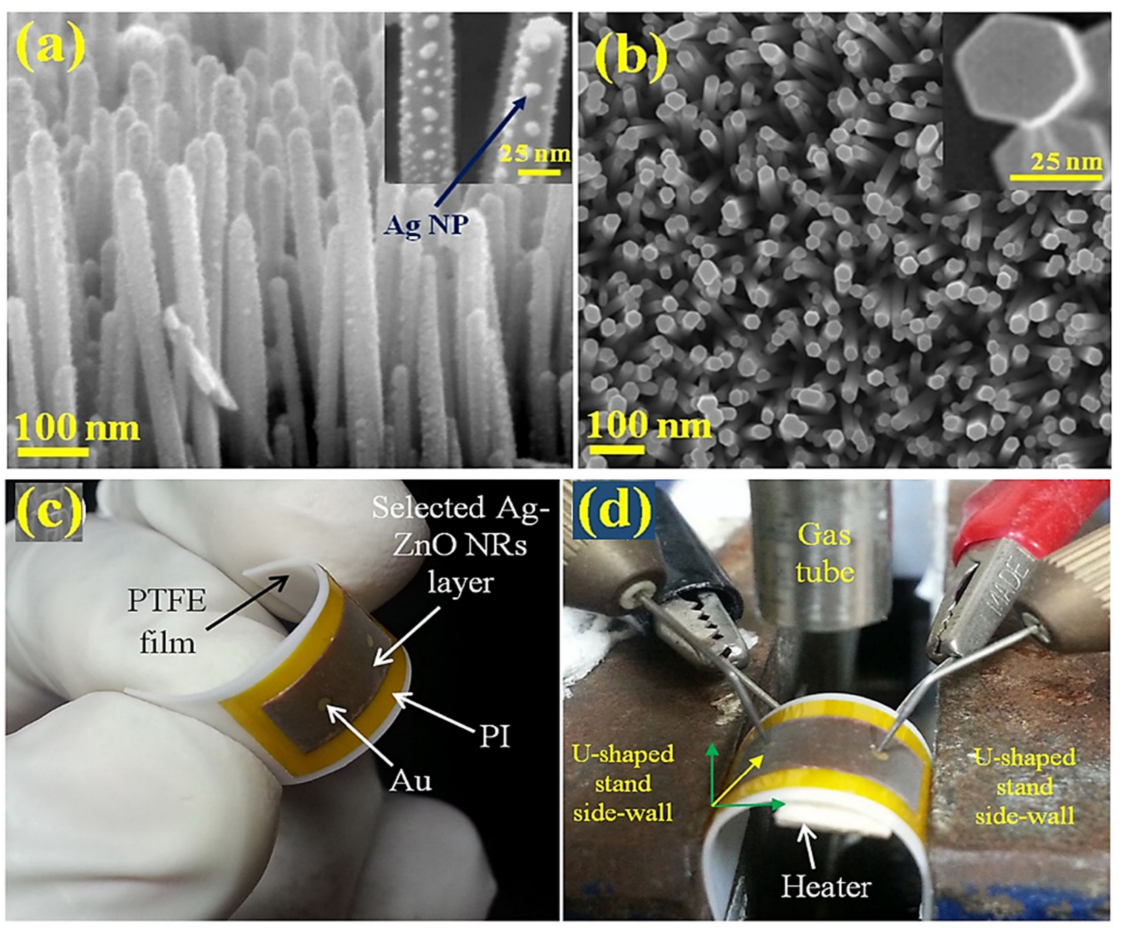

Figure 6. Images of (a) cross-section and (b) in-plane view of $8 \mathrm{~s}$ Ag-loaded ZnO NRs, (c) the Agdecorated $\mathrm{ZnO}$ flexible gas sensor, and (d) the experimental setup at one bending angle. Reprinted from reference [54] with permission from Elsevier. 
Flexible gas sensors should have the following characteristics: (i) the ability to detect gases at low concentrations and (ii) low- or room-temperature operation [55]. In this study, radio frequency magnetron sputtering ( $125 \mathrm{~W}, 7$ mTorr) was applied to load Ag NPs onto the sensing layer of $\mathrm{ZnO} \mathrm{NRs}$ in an Ar environment at different loading times of 6, 8, and $10 \mathrm{~s}$. Gas-sensing analysis demonstrated that the flexible sensor developed using $8 \mathrm{~s}$ Ag-loaded $\mathrm{ZnO}$ NRs showed a higher response of 13.8 toward $100 \mathrm{ppm} \mathrm{C}_{2} \mathrm{H}_{2}$ at $200{ }^{\circ} \mathrm{C}$ than those of the pristine (3.21), $6 \mathrm{~s}$ (9.33), and $10 \mathrm{~s}$ (9.57) Ag-loaded sensors. Furthermore, upon repeated bending and relaxation for up to $5 \times 10^{4}$ cycles, the sensor response only slightly decreased, which demonstrated the outstanding sustainability and mechanical strength of the designed flexible sensor. This performance improvement was attributed to the integration of the $\mathrm{Ag}-\mathrm{ZnO}$ structure with the flexible PI substrate, which improved the physical binding and adherence of the $\mathrm{Ag}-\mathrm{ZnO}$ structure to the supporting substrate. $\mathrm{ZnO}$ NRs with small diameters ensured an improved surface area and a larger aspect ratio of the resulting sensor. This caused inadequate surface atomic coordination and higher surface energy, leading to better adsorption of $\mathrm{O}$ ions and hence improved sensor response. Furthermore, because of catalytic interactions, the $\mathrm{Ag} \mathrm{NP} / \mathrm{ZnO}$ NR interface might produce further charge carriers or $\mathrm{O}$ vacancies on the sensor surface. In the case of Ag-loaded $\mathrm{ZnO}$ $\mathrm{NRs}$, the $\mathrm{ZnO}$ surface transformed from an electron-depletion state to an almost flat band state along with a redox change at $\mathrm{Ag}$. Additionally, the improved $\mathrm{C}_{2} \mathrm{H}_{2}$ sensing activity observed at an optimum temperature of $200{ }^{\circ} \mathrm{C}$ was ascribed to the height of the Schottky barrier between the $\mathrm{ZnO}$ grains and $\mathrm{Ag}$ in the Ag-loaded $\mathrm{ZnO}$ NRs. The improvement in the performance of the Ag-loaded $\mathrm{ZnO}$ NRs may also be controlled by changing the Ag concentration for the sensitive variation of the Ag oxidation state during exposure to $\mathrm{C}_{2} \mathrm{H}_{2}$. When the Ag loading amount was high, a thick Ag layer developed on the ZnO NR surface, which decreased the efficacy of the open surface porosity of $\mathrm{ZnO}$, thereby reducing the gas sensor response. Herein, the observed higher selectivity of the $\mathrm{Ag} / \mathrm{ZnO}$ NR sensor toward $\mathrm{C}_{2} \mathrm{H}_{2}$ was attributed to the chemical sensitization effect. Since Ag has excellent catalytic activity, it acts as a certain adsorption site for the dissociation of $\mathrm{O}_{2}$ and separation of $\mathrm{H}_{2}$ molecules owing to the spillover effect.

\subsection{Ag-Decorated/Loaded Triethylamine (TEA) Gas Sensors}

TEA, a clear and flammable liquid with a strong odor of ammonia, is widely used in chemical industries [56]. However, TEA can cause many severe health issues, such as pulmonary edema, gastroenteritis, headaches, and even death, because of its toxicity [57]. Additionally, dead fish and other decaying marine products may release TEA, and the concentration of TEA is expected to progressively increase over time [58]. Consequently, TEA may serve as a chemical indicator to assess the quality of marine food [59]. Therefore, designing an advanced sensor for the detection and monitoring of TEA is required. In contrast, recently, three-dimensional (3D) structural nanomaterials have received considerable attention in gas-sensing applications. In fact, 3D structures may offer highly efficient specific surface areas that improve the response of the corresponding gas sensor. Accordingly, Shen et al. [60] reported the TEA sensing characteristics of Ag-loaded 3D porous $\mathrm{ZnO}$ microspheres. Their morphological studies indicated that the $\mathrm{ZnO}$ microspheres (3-5 $\mu \mathrm{m}$ in size) were assembled by numerous thin and porous nanosheets with sizes of $\approx 20 \mathrm{~nm}$. The developed sensor exhibited better cross-selectivity toward TEA, which was significantly attributed to the differences between the reactivity of the target gases caused by their different bond energies and chemical molecular structures. The reported C-N, C-O, $\mathrm{C}-\mathrm{H}, \mathrm{C}=\mathrm{C}, \mathrm{C}=\mathrm{O}$, and $\mathrm{O}-\mathrm{H}$ bond energies are $307,326,414,610.3,798.9$, and $458.8 \mathrm{~kJ} / \mathrm{mol}$, respectively. As a result of the lower $\mathrm{C}-\mathrm{N}$ bond energy, the TEA molecules were more easily reduced by $\mathrm{Ag}-\mathrm{ZnO}$.

In this case, the baseline resistance of the Ag-loaded sensor $(2737.8 \mathrm{M} \Omega$ ) was higher than that of the pristine sensor $(28.5 \mathrm{M} \Omega)$. Furthermore, O species may more readily adsorb on the Ag NPs via a known spillover effect. Thus, highly active negative $\mathrm{O}$ ions spilled on the $\mathrm{ZnO}$ surface, which extracted the electrons from the conduction band of 
$\mathrm{ZnO}$, thereby increasing the thickness of the electron-depletion layer and consequently the sensor resistance. Furthermore, the active $\mathrm{O}$ species accelerated the reaction of the sensor with TEA. Overall, the widely dispersed Ag NPs were highly favorable to the spillover effect and might catalyze the sensing reaction to increase the response of the sensor to TEA (Figure 7a,b). Finally, the special hierarchical 3D porous nanostructure comprised hundreds of porous nanosheets was an additional meaningful component for the excellent TEA sensing properties of the Ag-loaded gas sensor. This unique structure with a high surface area and large pores (Figure $7 \mathrm{c}, \mathrm{d}$ ) increased the regions of the sensing reaction and promoted the TEA sensing performance of the sensor.

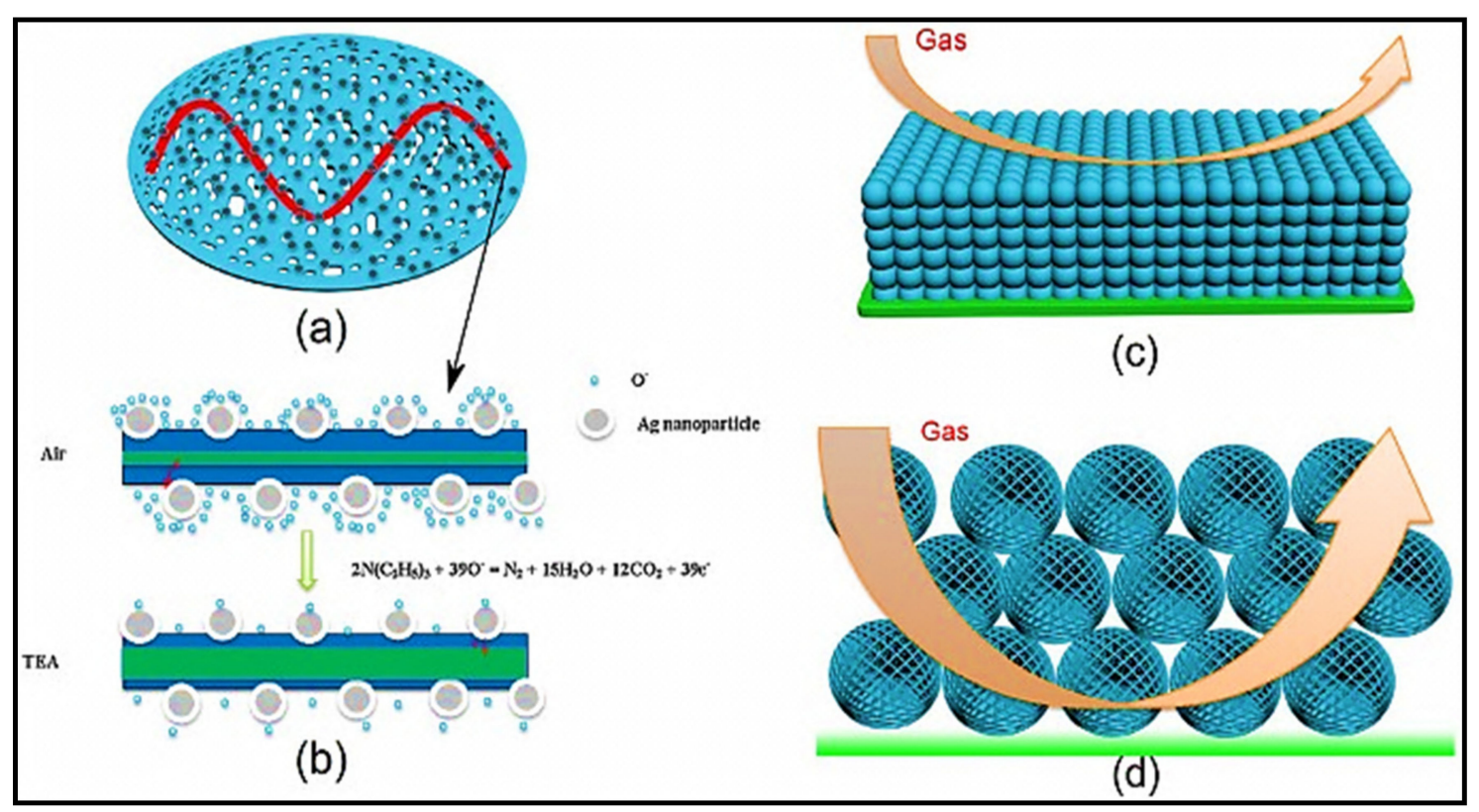

Figure 7. Schematic of the $(\mathbf{a}, \mathbf{b})$ TEA gas-sensing mechanism of the Ag-ZnO sensor and $(\mathbf{c}, \mathbf{d})$ structures of the microspheres with the illustration of large pores. Reprinted from reference [60] with permission from Elsevier.

\subsection{Ag-Decorated/Loaded Formaldehyde (HCHO) Gas Sensors}

$\mathrm{HCHO}$ is extensively utilized in several industrial applications. Typically, $\mathrm{HCHO}$ is a colorless gas with a pungent odor, and it easily evaporates from the products into the indoor air. Many health-related issues, including headaches, nausea, cancer, and mucosal and respiratory irritation, are associated with exposure to HCHO [61-64]. Therefore, the development of highly sensitive $\mathrm{HCHO}$ gas sensors is urgently required to ensure the safety of people. In this regard, Xing et al. [65] prepared highly porous 1-5 at \% Ag-loaded ZnO for application in $\mathrm{HCHO}$ sensors. In this study, the sensor fabricated using 1 at \% Ag-loaded $\mathrm{ZnO}$ exhibited the maximum response to $\mathrm{HCHO}(170.42)$ at an optimal temperature of $240{ }^{\circ} \mathrm{C}$. Unique hierarchically structured porous Ag-loaded $\mathrm{ZnO}$ provided an adequate surface area for interaction between the $\mathrm{HCHO}$ molecules and the sensing material. The high response of the optimal gas sensor to $\mathrm{HCHO}$ was ascribed to the production of heterojunctions between $\mathrm{Ag}$ and $\mathrm{ZnO}$ in addition to the catalytic activity of Ag. Schematics of the energy bands of $\mathrm{Ag} / \mathrm{ZnO}$ in the presence of air and $\mathrm{HCHO}$ gas are shown in Figure 8a,b, respectively. Herein, the electrons transferred from $\mathrm{Ag}$ to $\mathrm{ZnO}$ because the work function of $\mathrm{Au}(\mathrm{Wm}=4.4 \mathrm{eV})$ is smaller than that of $\mathrm{ZnO}(\mathrm{Ws}=5.2 \mathrm{eV})$, generating an electron-depletion layer because of the increase in the concentration of electrons at the $\mathrm{Ag} / \mathrm{ZnO}$ interface. When the $\mathrm{Ag} / \mathrm{ZnO}$ sensor was exposed to air, the electrons released from $\mathrm{ZnO}$ were captured by the adsorbed $\mathrm{O}$ ions to form $\mathrm{O}^{-} \mathrm{x}$, which showed strong oxidation activity. This process reduced the sensor resistance. Upon exposure to $\mathrm{HCHO}$, the previously adsorbed $\mathrm{O}^{-}$x strongly reacted with the $\mathrm{HCHO}$ molecules and oxidized $\mathrm{HCHO}$ into $\mathrm{CO}_{2}$ and $\mathrm{H}_{2} \mathrm{O}$, thereby decreasing the sensor resistance. This study reveals that the 
$\mathrm{HCHO}$ sensing performance of the sensor is directly influenced by the $\mathrm{Ag} / \mathrm{ZnO}$ heterojunction and the developed $\mathrm{O}^{-}$.

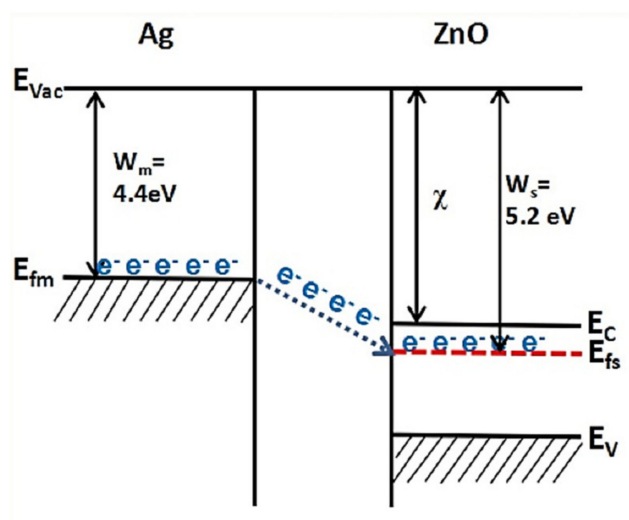

(a)

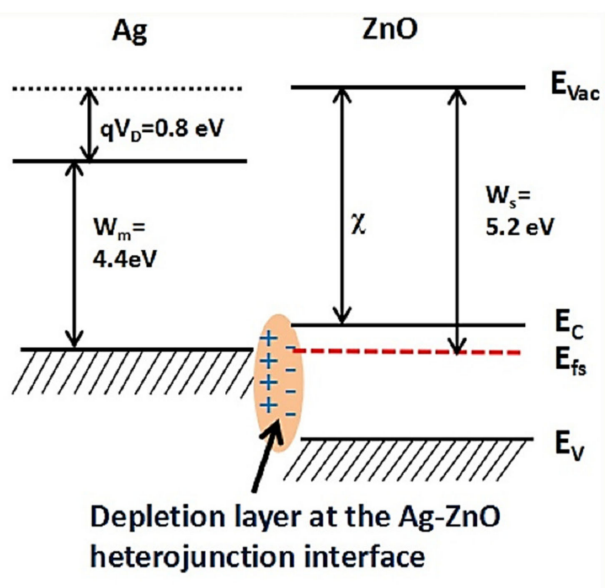

(b)

Figure 8. Schematics of the band structures of Ag-loaded $\mathrm{ZnO}$ in (a) air and (b) HCHO. Reprinted from reference [65] with permission from Elsevier.

Furthermore, Wang et al. [66] reported the HCHO sensing activity of a two-step solution-processed Ag-loaded sunflower-like hierarchical $\operatorname{In}_{2} \mathrm{O}_{3}$ nanoarchitecture. The observed $\mathrm{HCHO}$ sensing performance was attributed to the highly porous and hierarchically designed sunflower-like nanostructure and the catalytic activity of Ag. The exclusive hierarchical 3D sunflower-like nanostructures possess numerous radial nanobranches with irregular surfaces, which offer a larger exposed surface area and additional paths for the exchange of electrons during the entire gas diffusion and surface reaction processes. An appropriate Ag loading amount plays an important role in chemical and electronic sensitization during the detection of $\mathrm{HCHO}$ by the Ag-loaded $\mathrm{In}_{2} \mathrm{O}_{3}$ sensor. Chemical sensitization favored gas reactions by dissociating $\mathrm{HCHO}$ via a spillover effect, and electronic sensitization substantially enhanced the direct exchange of electrons between $\mathrm{In}_{2} \mathrm{O}_{3}$ and Ag. However, higher Ag loading amount resulted in the conduction of electrons along the metallic Ag NPs irrespective of chemoresistive variations, thereby deteriorating the sensor response.

\subsection{Ag-Decorated/Loaded Carbon Monoxide (CO) Gas Sensors}

$\mathrm{CO}$ is among the most hazardous gases as it is invisible, tasteless, odorless, and colorless and thus cannot be detected by human sensory organs [67]. Consequently, numerous efforts have been made to detect $\mathrm{CO}$ gas by various materials and strategies. Molybdenum disulfide $\left(\mathrm{MoS}_{2}\right)$ is a distinct graphene-like two-dimensional (2D) layered transition metal dichalcogenide. In addition to a conventional band gap of $1.8 \mathrm{eV}$, it has a large surface area-to-volume ratio with excellent physical/mechanical properties [68]. Nevertheless, the gradual degradation of $\mathrm{MoS}_{2}$ nanosheets occurs under ambient conditions owing to atmospheric oxidation and surface contamination, which may eventually decrease their sensing performances. Thus, to achieve an appropriate $\mathrm{CO}$ sensing performance of pure $\mathrm{MoS}_{2}$ nanosheets, sensing should be performed under an inert $\mathrm{N}_{2}$ atmosphere, significantly restricting their commercial applications. To overcome this limitation, Zhang et al. [69] fabricated a novel ternary Ag-loaded $\mathrm{ZnO} / \mathrm{MoS}_{2}$ nanocomposite via layer-by-layer selfassembly for the detection of $\mathrm{CO}$ gas.

The presence of $\mathrm{ZnO}$ NRs, $\mathrm{Ag}$ NPs, and $\mathrm{MoS}_{2}$ nanosheets was verified by morphological investigations (the scanning electron microscopy (SEM) image is shown in Figure 9a). The developed nanocomposite sensor demonstrated excellent room temperature $\mathrm{CO}$ sensing performance. This confirmed that the existence of $\mathrm{MoS}_{2}$ might reduce the operating temperature and energy consumption probably because of the higher specific surface area and better conductivity 
of $\mathrm{MoS}_{2}$ along with the synergistic effect between $\mathrm{ZnO}$ and $\mathrm{MoS}_{2}$. Ag effectively improved the catalytic activity of the sensor and mobilities of the carriers for the interaction of gas with the surface of $\mathrm{MoS}_{2}$ or $\mathrm{ZnO}$ by modifying the energy band structure and surface morphology of the sensing material. Furthermore, substantial dynamic sites for $\mathrm{CO}$ adsorption might be generated upon $\mathrm{Ag}$ loading. After Ag modification, the interactions of $\mathrm{CO}$ molecules with $\mathrm{O}$ ions dramatically reduced the resistance of the $\mathrm{Ag}-\mathrm{ZnO} / \mathrm{MoS}_{2}$ nanocomposites as compared to that of the $\mathrm{ZnO} / \mathrm{MoS}_{2}$ film, resulting in a high $\mathrm{CO}$ response of the sensor. A schematic of the interactions between the $\mathrm{CO}$ molecules and the $\mathrm{Ag}-\mathrm{ZnO} / \mathrm{MoS}_{2}$ sensor is depicted in Figure $9 \mathrm{~b}$. Herein, $\mathrm{Ag}$ and $\mathrm{Pt}$ were employed to improve the $\mathrm{CO}$ sensing performance of the $\mathrm{ZnO} / \mathrm{MoS}_{2}$ composite sensor. The Ag-loaded sensor exhibited the maximum response as compared to that of the Pt-loaded sensor under similar experimental conditions. The higher response of the Ag-loaded sensor was explained with respect to the work function. Upon the introduction of a noble metal into $\mathrm{ZnO} / \mathrm{MoS}_{2}$, the electrical characteristics of $\mathrm{ZnO} / \mathrm{MoS}_{2}$ may be influenced by the existence of a Schottky barrier. Therefore, noble metals with lower work functions are preferred to reduce the Schottky barrier and thus improve the response of the corresponding $\mathrm{ZnO} / \mathrm{MoS}_{2}$ sensor. As $\mathrm{Ag}$ has a lower work function $(4.26 \mathrm{eV})$ than that of $\mathrm{Pt}(5.65 \mathrm{eV})$, the $\mathrm{Ag}-\mathrm{ZnO} / \mathrm{MoS}_{2}$-based sensor demonstrated higher $\mathrm{CO}$ sensing performance.
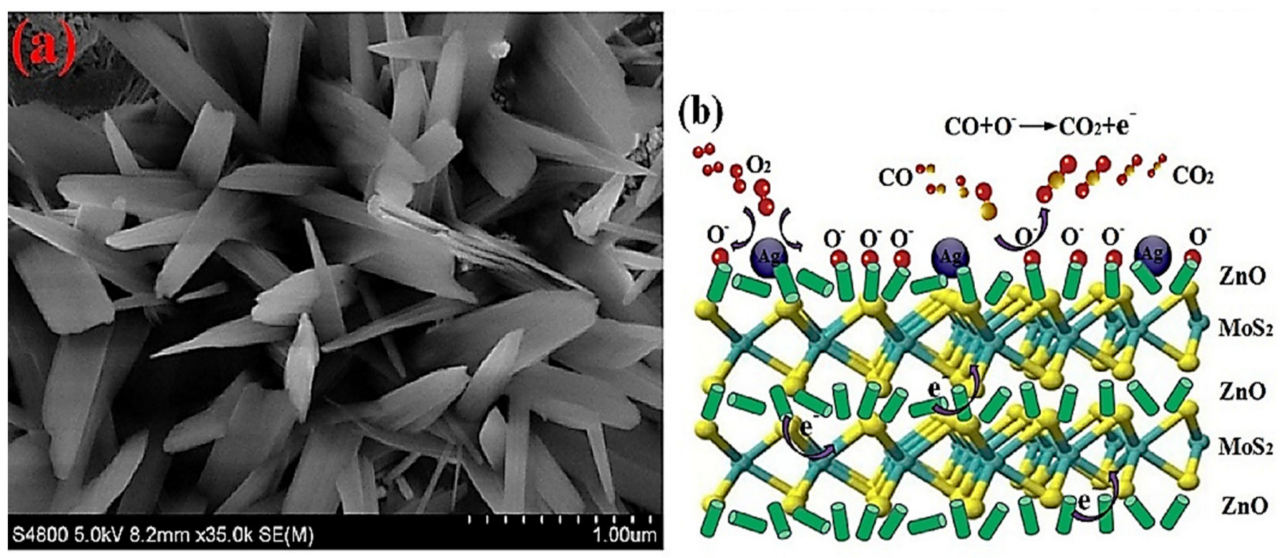

Figure 9. (a) SEM image of $\mathrm{Ag}-\mathrm{ZnO} / \mathrm{MoS}_{2}$ and (b) schematic of the $\mathrm{CO}$ sensing mechanism of $\mathrm{Ag}-\mathrm{ZnO} / \mathrm{MoS}_{2}$. Reprinted from reference [69] with permission from Elsevier.

In another study, Ag-modified flower-like $\mathrm{ZnO}$ microspheres were prepared using a combination of solvothermal strategy and an impregnation approach [70]. Dual selective sensing of methane $\left(\mathrm{CH}_{4}\right)$ and $\mathrm{CO}$ using 1.5 at \% Ag-loaded $\mathrm{ZnO}$ by monitoring the working temperature was reported in this study. Ag exhibits high catalytic activity for low-temperature oxidation of $\mathrm{CO}$. However, the low-temperature oxidation of $\mathrm{CH}_{4}$ is very difficult to achieve, as $\mathrm{CH}_{4}$ is a thermally stable $\mathrm{sp}^{3}$-hybridized non-polar molecule. Accordingly, no considerable low-temperature response of the sensor to $\mathrm{CH}_{4}$ was observed. In contrast, at higher temperatures, $\mathrm{CH}_{4}$ was sufficiently activated by Ag because there was adequate thermal energy to overcome the barrier, thereby increasing the sensor response. Consequently, the sensor fabricated using 1.5 at \% Ag-loaded $\mathrm{ZnO}$ exhibited temperaturemodulated dual selectivity toward $\mathrm{CO}$ and $\mathrm{CH}_{4}$ at 130 and $200^{\circ} \mathrm{C}$, respectively.

\subsection{Ag-Decorated/Loaded Ethanol $\left(\mathrm{C}_{2} \mathrm{H}_{5} \mathrm{OH}\right)$ Gas Sensors}

$\mathrm{C}_{2} \mathrm{H}_{5} \mathrm{OH}$ is one of the most commonly used VOCs. Exposure to $\mathrm{C}_{2} \mathrm{H}_{5} \mathrm{OH}$ vapors may cause headache, drowsiness, eye irritation, liver damage, and breathing difficulties. Furthermore, the consumption of $\mathrm{C}_{2} \mathrm{H}_{5} \mathrm{OH}$ is the leading cause of motor vehicle accidents worldwide, and alcohol-impaired driving fatalities account for $31 \%$ of the total number of traffic-related deaths in the United States [71]. Thus, the design of low-temperature operating and selective sensors for the detection and monitoring of $\mathrm{C}_{2} \mathrm{H}_{5} \mathrm{OH}$ is required from the viewpoint of safety. Graphitic carbon nitride $\left(\mathrm{gC}_{3} \mathrm{~N}_{4}, \mathrm{~g}-\mathrm{CN}\right)$ is a non-metallic polymer semiconductor with a $2 \mathrm{D}$ layered structure. As a result of its unique physicochemical 
characteristics, suitable band gap, and outstanding thermal and chemical stabilities, g-CN can be utilized as an active sensing element in gas-sensing applications. In this regard, Tomer et al. [72] fabricated well-ordered mesoporous Ag-decorated meso-CNs using a hard template by nanocasting to detect $\mathrm{C}_{2} \mathrm{H}_{5} \mathrm{OH}$ at trace levels. The response of cubic meso- $\mathrm{CN}$ to $\mathrm{C}_{2} \mathrm{H}_{5} \mathrm{OH}$ gas was approximately two times that of conventional g-CN. This improvement was caused by the higher meso-CN surface area along with uniform pore channels through which the target gas penetrated the deep portions of the sensor. The response of the $3 \mathrm{wt} . \%$ Ag-decorated meso-CNs to $\mathrm{C}_{2} \mathrm{H}_{5} \mathrm{OH}$ gas was two times that of meso-CN. A schematic of the $\mathrm{C}_{2} \mathrm{H}_{5} \mathrm{OH}$ sensing mechanism of the $\mathrm{Ag} / \mathrm{g}-\mathrm{CN}$ sensor is shown in Figure 10. In this case, the electrons transferred from g-CN to Ag due to the lower work function of g-CN $(4.3 \mathrm{eV})$ than that of $\mathrm{Ag}(4.7 \mathrm{eV})$, thereby creating a potential barrier. This barrier prevented the transfer of electrons through the mesoporous sensor, and the electrons existing on the sensor surface developed dynamic sites for the adsorption of $\mathrm{O}_{2}$, thereby increasing the sensor response. Moreover, the loading of Ag NPs strongly accelerated catalytic oxidation and chemical sensitization, which ultimately enhanced the number of dynamic $\mathrm{O}$ species on the surface of meso-CN. In fact, the chemical sensitization effect (namely, spillover effect) of Ag NPs improved the rate of adsorption-desorption of molecular $\mathrm{O}_{2}$ on the sensor surface and transformed molecular $\mathrm{O}_{2}$ into $\mathrm{O}$ ions. Furthermore, the excellent catalytic activity of Ag NPs accelerated the decomposition of $\mathrm{C}_{2} \mathrm{H}_{5} \mathrm{OH}$ gaseous molecules into active radicals, thus enhancing the interactions between the chemisorbed $\mathrm{O}$ ions and $\mathrm{C}_{2} \mathrm{H}_{5} \mathrm{OH}$ molecules. Owing to the transfer of electrons from meso-CN to Ag NPs, a negatively charged layer was produced around the $\mathrm{Ag} /$ meso- $\mathrm{CN}$ interface. Under a $\mathrm{C}_{2} \mathrm{H}_{5} \mathrm{OH}$ atmosphere, the electrons returned to the sensing layer via the $\mathrm{Ag}_{2} \mathrm{O} / \mathrm{Ag}$ redox reaction, and thus, the areas along the $\mathrm{Ag} /$ meso- $\mathrm{CN}$ interface became very sensitive to $\mathrm{C}_{2} \mathrm{H}_{5} \mathrm{OH}$.

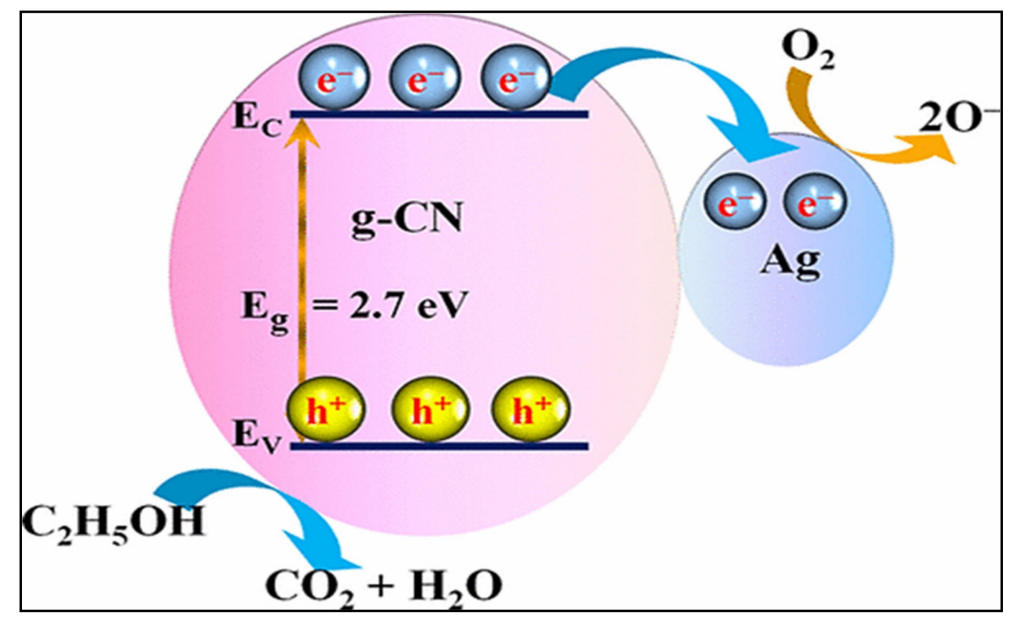

Figure 10. Band diagram of the $\mathrm{Ag} / \mathrm{g}-\mathrm{CN}$ sensor, elucidating the $\mathrm{C}_{2} \mathrm{H}_{5} \mathrm{OH}$ sensing mechanism of the sensor [72]. Reprinted from https:/ / pubs.acs.org/doi/10.1021/acsomega.7b00479 (accessed on July 14,2017 ) with permission from ACS (further permissions related to the material excerpted should be directed to the ACS).

\subsection{Ag-Decorated/Loaded Nitrogen Dioxide $\left(\mathrm{NO}_{2}\right)$ Gas Sensors}

$\mathrm{NO}_{2}$ is a highly poisonous and polluting gas that produces acid rain and photochemical smog [73]. As a result of its highly toxic nature, detection and monitoring systems for $\mathrm{NO}_{2}$ are needed. Accordingly, Wang et al. conducted $\mathrm{NO}_{2}$ gas-sensing studies employing Ag-loaded mesoporous $\mathrm{WO}_{3}$ designed using 3D cubic KIT-6 as a hard template [74]. Herein, $\mathrm{Ag}$ at different molar ratios of $0.2,0.5$, and $1.0 \%$ was loaded onto mesoporous $\mathrm{WO}_{3}$. The sensor developed using $0.5 \%$ Ag exhibited a higher response of 44 to $1 \mathrm{ppm} \mathrm{NO}_{2}$ at $75^{\circ} \mathrm{C}$ because of its larger surface area and diffusion paths. $\mathrm{NO}_{2}$ is a polar molecule having a positive charge localized on the $\mathrm{N}$ atom and a negative charge over the $\mathrm{O}$ atom. The interaction of electrons with $\mathrm{Ag}$ repels the $\mathrm{O}$ atom and attracts the positively charged $\mathrm{N}$ 
atom. Ag was used as a dynamic catalyst to create more active sites for the detection of $\mathrm{NO}_{2}$. Although the addition of Ag may enhance the sensing properties of the material, the loading of Ag at excessively high concentrations can decrease the catalytic performance of the material. When the $\mathrm{Ag}$ concentration exceeded $0.5 \%$, the total surface area reduced, and interconnected $\mathrm{Ag}$ NPs changed the electron path to be from $\mathrm{Ag}$ instead of $\mathrm{WO}_{3}$.

The advantages of UV-activated sensors are their high stabilities, abilities to detect flammable gases, and low energy consumptions. In a typical UV-based gas-sensing device, the UV wavelength and power intensity determine the energy of the photons arriving at the exposed surface. This energy influences the steady-state surface reactions and plays a significant role in the response curve. Espid et al. [75] explained the $\mathrm{NO}_{2}$ gas detection characteristics of Ag-loaded $\mathrm{ZnO}$ nanoellipsoids, which were synthesized by a simple coprecipitation method, under UV illumination. When the surface of the gas sensor was irradiated with the photons released from a UV light-emitting diode, the electrons of the sensor hopped from the valence band to the conduction band, leaving holes in the valence band. A schematic of electron mobilization and the related reactions of the Ag-loaded $\mathrm{ZnO}$ sensor with $\mathrm{NO}_{2}$ gas under $\mathrm{UV}$ illumination is depicted in Figure 11. Photogenerated electron/hole pairs supported the direct adsorption of $\mathrm{O}_{2}$ molecules. Under an air atmosphere, $\mathrm{O}_{2}$ interacted with the excited electrons and adsorbed in the ionic form on the sensor surface. This slightly increased the sensor resistance. Under a $\mathrm{NO}_{2}$ atmosphere, the gas molecules reacted with the chemisorbed oxygen ions or directly adsorbed on the sensor surface by accepting electrons. A change in the electron flow stimulated by these reactions modulated the electrical resistivity. Under continuous UV irradiation, when the $\mathrm{NO}_{2}$ flow was stopped, the accelerated photons eliminated the $\mathrm{NO}_{2}$ species from the sensor surface. The observed enhancement in the $\mathrm{NO}_{2}$ detection performance of $\mathrm{ZnO}$ nanoellipsoids after Ag loading was associated with the synergistic effects of the semiconductor composite and $\mathrm{Ag}$. Additionally, the improvement of the sensing response in the presence of Ag was linked to the increased electron utilization ratio and the decreased recombination rate of photogenerated electrons and holes due to the trapping of electrons in the Ag NPs during excitation. Similarly, the adsorption ability was directly correlated with the number of unoccupied oxygen sites. When $\mathrm{Ag}$ was embedded in the $\mathrm{ZnO}$ lattice, O-vacancies formed because of the differences between the charges of $\mathrm{Ag}^{+}$and $\mathrm{Zn}^{2+}$ ions, which indicated that additional adsorption sites were created, resulting in a higher sensor response.

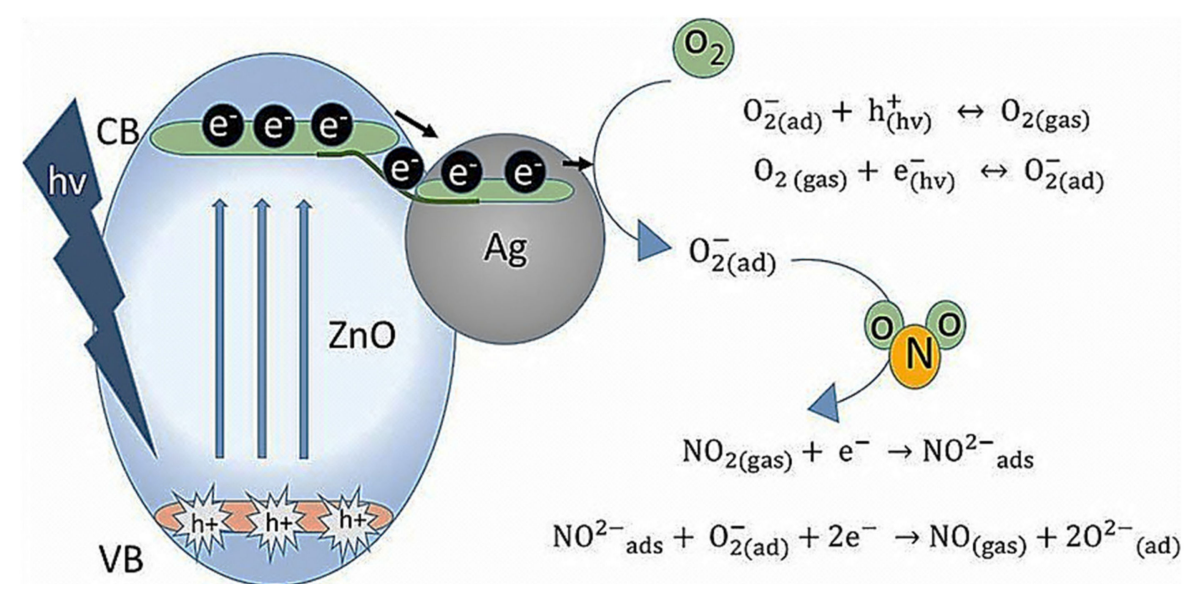

Figure 11. Schematic of electron mobilization and related reactions of the $\mathrm{Ag}-\mathrm{ZnO}$ sensor in the presence of $\mathrm{NO}_{2}$ gas [75]. Reproduced from https:/ / iopscience.iop.org/article/10.1149/2.0141807jss (accessed on 10 April 2018) from IOPScience (This is an open access article distributed under the terms of the Creative Commons Attribution Non-Commercial No Derivatives 4.0 License (CC BY-NC-ND, http:/ / creativecommons.org/licenses/by-nc-nd/4.0/ (accessed on 10 April 2018))).

Furthermore, Zhang et al. [76] designed a room-temperature light-assisted $\mathrm{NO}_{2}$ gas sensor using Ag-decorated $\mathrm{ZnO}$ NPs. The sensor developed using 3 mol.\% Ag exhibited the highest $\mathrm{NO}_{2}$ response. A schematic of the $\mathrm{NO}_{2}$ detection mechanism of pure and $\mathrm{Ag}$-loaded 
$\mathrm{ZnO}$ NPs under various light conditions is shown in Figure 12. Herein, characterization studies revealed the development of a heterojunction between Ag NPs and ZnO NPs. Nevertheless, the improved $\mathrm{NO}_{2}$ detection performance of the sensor after $\mathrm{Ag}$ loading was ascribed to prominent interactions between Ag NPs and the O vacancies. In this study, $\mathrm{Ag}$ NPs and surface oxygen vacancies acted as electron sinks to boost charge separation and catalytic activities of Ag NPs for promoting the adsorption of gas molecules. The effective separation of photogenerated electron-hole pairs due to the interfacial charge transfer between $\mathrm{ZnO}$ and $\mathrm{Ag}$ and charge-carrier trapping through the surface oxygen vacancies enabled further accumulation of unpaired electrons on the surfaces of $\mathrm{ZnO}$ NPs. Moreover, Ag NPs and oxygen vacancies on the surface enhanced the adsorption of gas molecules, and thus, more oxygen molecules adsorbed on the sensor surface. An excess of Ag NPs reversibly acted as charge-carrier recombination centers, leading to negatively charged electrostatic attraction between Ag and the positively charged holes, thereby reducing the photoquantum efficiency. Additionally, sometimes, it is difficult to completely desorb the molecular or atomic oxygen species chemisorbed on the Ag surface through light irradiation at room temperature. In brief, $\mathrm{O}_{2}$ molecules play an essential role in the absorption/desorption of $\mathrm{NO}_{2}$ molecules on the surfaces of $\mathrm{ZnO}$ NPs. Specifically, the exposure degree of $\mathrm{O}^{-}$2(ads) $(\mathrm{h} v)$ directly stimulates the sensing characteristics, such as response and response/recovery speeds, of light-assisted $\mathrm{NO}_{2}$ sensors.
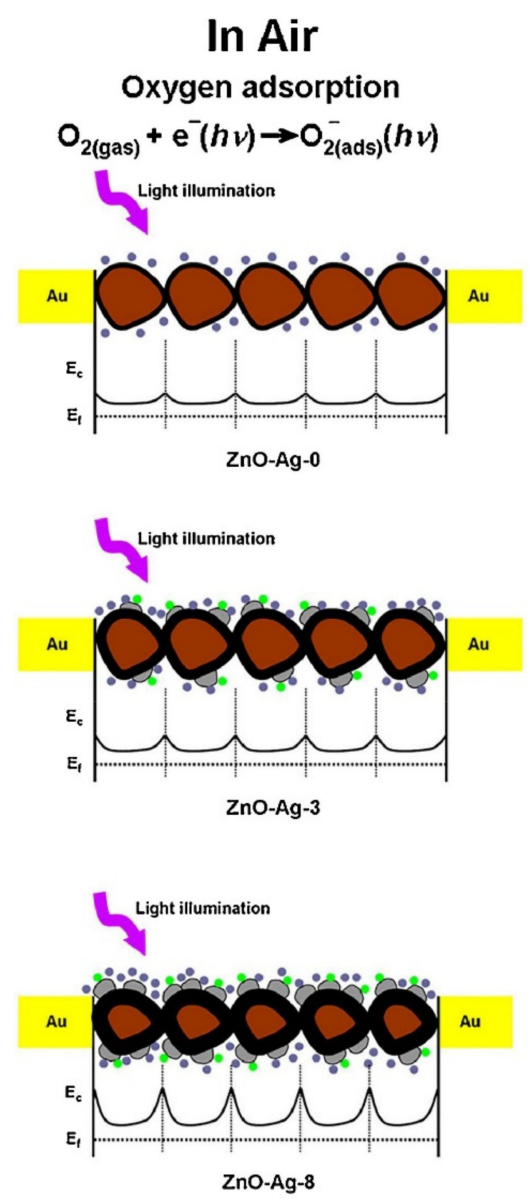

\section{In $\mathrm{NO}_{2}$}

\section{Nitrogen dioxide adsorption}
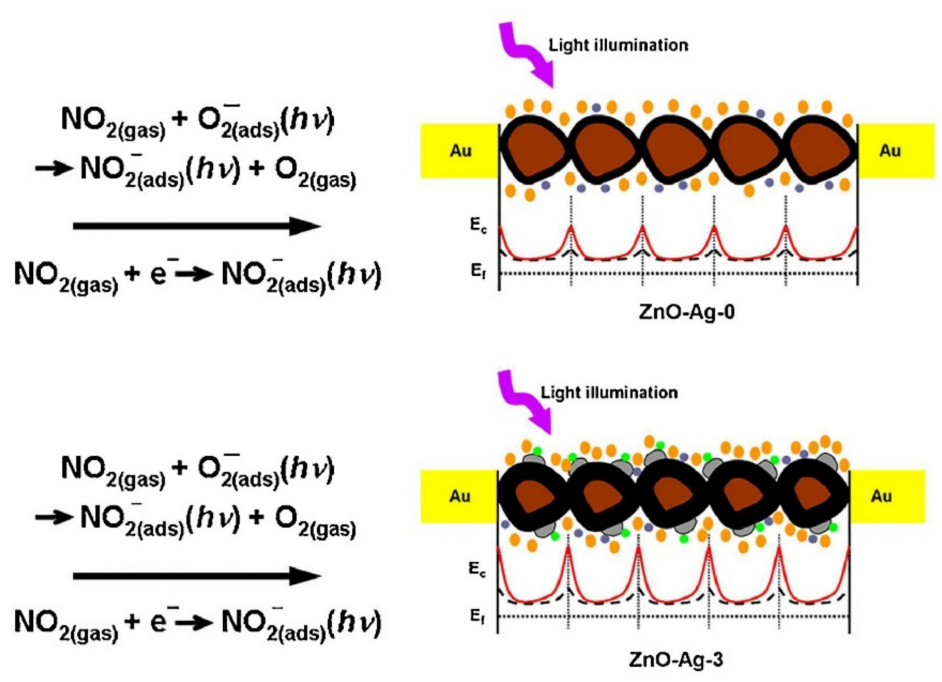
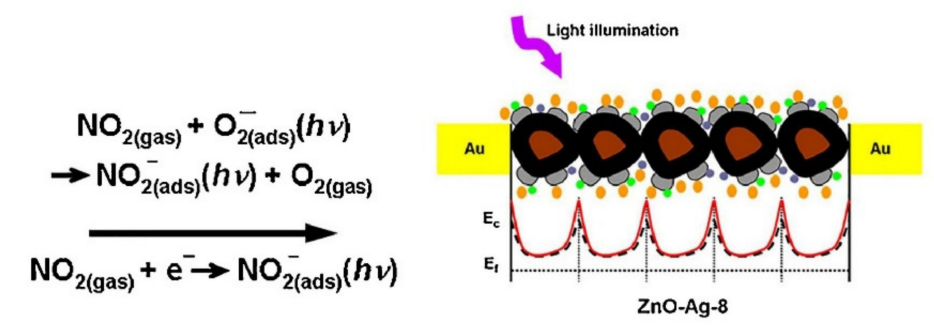

Molecular or atomic oxygen species chemisorbed on Ag surface

$\mathrm{O}_{2(\mathrm{ads})}^{-}(\boldsymbol{h} v) \bigcirc \mathrm{NO}_{2(\mathrm{ads})}^{-}(h v)$

\section{ZnO nanoparticle Ag nanoparticle Depletion layer}

Figure 12. Schematic of the $\mathrm{NO}_{2}$ gas detection mechanism of pristine and Ag-loaded $\mathrm{ZnO}$ NPs irradiated with light of 365-520 nm wavelengths. Reprinted from reference [76] with permission from Elsevier. 


\subsection{Ag-Decorated/Loaded Methyl Mercaptan $\left(\mathrm{CH}_{3} \mathrm{SH}\right)$ Gas Sensors}

$\mathrm{CH}_{3} \mathrm{SH}$ is a gas that is commonly used as an additive to other gases including propane and natural gas. The rotten egg odor of $\mathrm{CH}_{3} \mathrm{SH}$ facilitates the detection of $\mathrm{CH}_{3} \mathrm{SH}$ leakage. The recommended airborne exposure limit for $\mathrm{CH}_{3} \mathrm{SH}$ is $0.5 \mathrm{ppm}$ during an $8 \mathrm{~h}$ work shift. Exposure to higher levels of $\mathrm{CH}_{3} \mathrm{SH}$ results in eye and throat irritation, drowsiness, and even bronchitis [77]. Consequently, designing a sensor that can detect $\mathrm{CH}_{3} \mathrm{SH}$ at low levels is highly desirable. Additionally, $\mathrm{CH}_{3} \mathrm{SH}$ gas-sensing properties of $\mathrm{SMOs}$ have rarely been reported. In this regard, Garcia et al. [77] constructed a sensor using mesoporous Ag-loaded hematite $\left(\alpha-\mathrm{Fe}_{2} \mathrm{O}_{3}\right)$ to detect $\mathrm{CH}_{3} \mathrm{SH}$ at room temperature. Herein, the loading of $3 \mathrm{wt} . \%$ Ag onto $\alpha-\mathrm{Fe}_{2} \mathrm{O}_{3}$ significantly enhanced the sensor response owing to the deeper electrondepletion layer. Ag loaded onto the surface of $\alpha-\mathrm{Fe}_{2} \mathrm{O}_{3}$ served as a catalyst to accelerate the rate of conversion of $\mathrm{O}_{2}$ into ionic $\mathrm{O}$. Therefore, more electrons were trapped, which generated a thicker depletion layer. When the Ag-loaded $\alpha-\mathrm{Fe}_{2} \mathrm{O}_{3}$ sensor was exposed to $\mathrm{CH}_{3} \mathrm{SH}$, the $\mathrm{CH}_{3} \mathrm{SH}$ molecules favorably chemisorbed due to the strong affinities of thiol groups for metallic $\mathrm{Ag}$. Ag loading accelerated the reaction of $\mathrm{CH}_{3} \mathrm{SH}$ with oxygen ions via a spillover effect (Figure 13). In this case, the deep electron-depletion layer converted into a flat layer, which resulted in a better sensor response. However, when the concentration of Ag exceeded $3 \mathrm{wt} . \%$, the Ag NPs generated a connected network on the surface of $\alpha-\mathrm{Fe}_{2} \mathrm{O}_{3}$, and consequently, the resistance of the sensor reduced. Thus, the adsorption of $\mathrm{O}_{2}$ and the gas- $\mathrm{O}_{2}$ interaction substantially reduced, causing an inferior response of the sensor to the target gas.

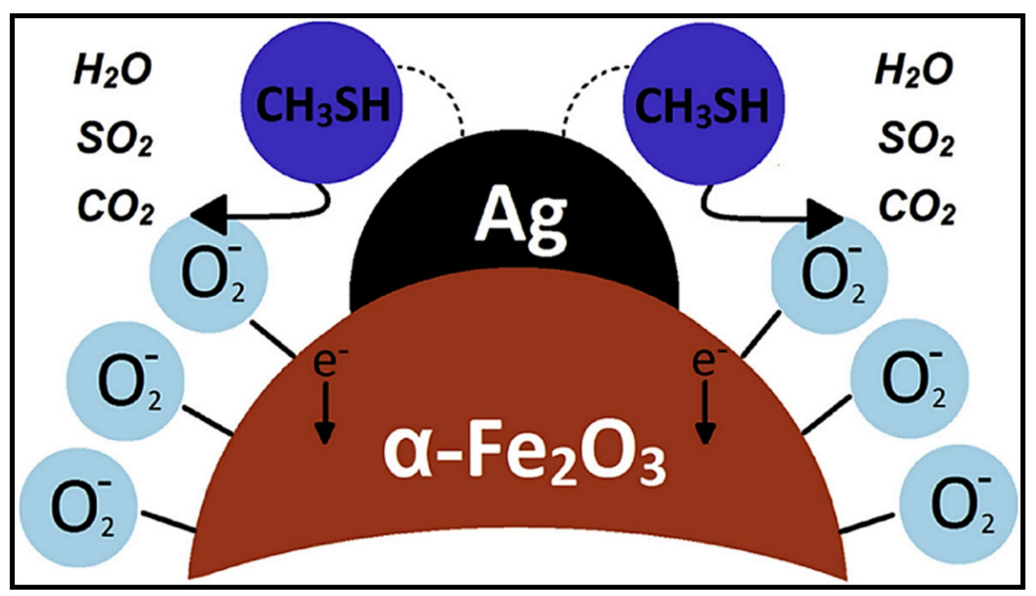

Figure 13. Schematic of the chemical influence of Ag NPs on the sensing mechanism of the $\alpha-\mathrm{Fe}_{2} \mathrm{O}_{3}$ sensor. Reprinted from reference [77] with permission from Elsevier.

\subsection{Ag-Decorated/Loaded Xylene $\left(\mathrm{C}_{8} \mathrm{H}_{10}\right)$ Gas Sensors}

$\mathrm{C}_{8} \mathrm{H}_{10}$ is a VOC that is colorless, odorless, and highly toxic in nature [78,79]. It causes severe damage to the human body, even at very low levels and upon long-term exposure [21]. Prolonged exposure to $\mathrm{C}_{8} \mathrm{H}_{10}$, even at low levels, is very harmful to living organisms; therefore, detection and monitoring of $\mathrm{C}_{8} \mathrm{H}_{10}$ is necessary. In a study reported by Zhang et al. [80], $\mathrm{C}_{8} \mathrm{H}_{10}$ detection properties of $0.2,0.5$, and 1 at \% Ag-loaded hedgehog-like $\mathrm{TiO}_{2}$ architectures are described. Herein, Ag-loaded hedgehog-like $\mathrm{TiO}_{2}$ nanostructures composed of hundreds of 1D NRs were synthesized via a simple hydrothermal process followed by isometric impregnation. Gas-sensing studies showed that the 0.5 at $\%$ Ag-loaded $\mathrm{TiO}_{2}$ sensor demonstrated the highest $\mathrm{C}_{8} \mathrm{H}_{10}$ response as compared to those of the 0.2 and 1 at $\% \mathrm{Ag}$-loaded $\mathrm{TiO}_{2}$ sensors. A schematic of the sensing interactions between the $\mathrm{C}_{8} \mathrm{H}_{10}$ gas molecules and $\mathrm{Ag} / \mathrm{TiO}_{2}$ is depicted in Figure 14. A typical gas-sensing mechanism of n-type SMOs, based on the change in resistance upon the interaction of these SMOs with gases, was used to explain the interactions between $\mathrm{C}_{8} \mathrm{H}_{10}$ and $\mathrm{Ag} / \mathrm{TiO}_{2}[65,66,77]$. The $\mathrm{C}_{8} \mathrm{H}_{10}$ responses observed for the pristine and 0.5 at $\% \mathrm{Ag}$ loaded $\mathrm{TiO}_{2}$ sensors were 3.19 and $\approx 6.49$ at $375{ }^{\circ} \mathrm{C}$, respectively. The sensor response reduced 
when the Ag loading amount was increased up to 1 at \%; this was mainly due to the coverage of the $\mathrm{TiO}_{2}$ surface sites by excessive Ag. Interestingly, all the Ag-loaded sensors exhibited fast responses and recovery dynamics; that is, the acquired response and recovery times were $\approx 5-7$ and $\approx 1-2 \mathrm{~s}$, respectively. The rapid response and recovery times were attributed to the strong electron mobility of the $1 \mathrm{D} \mathrm{TiO}_{2} \mathrm{NRs}$ and the superior porosity of the hedgehog-like Ag-loaded $\mathrm{TiO}_{2}$ architecture. The improvement in the $\mathrm{C}_{8} \mathrm{H}_{10}$ sensing characteristics of the $\mathrm{TiO}_{2}$ sensor upon Ag loading was ascribed to the catalytic activity of Ag and the development of $\mathrm{Ag} / \mathrm{TiO}_{2}$ heterojunctions. The catalytic $\mathrm{Ag}$ NPs facilitated more and quicker reactions between the adsorbed oxygen ions and the $\mathrm{C}_{8} \mathrm{H}_{10}$ molecules.

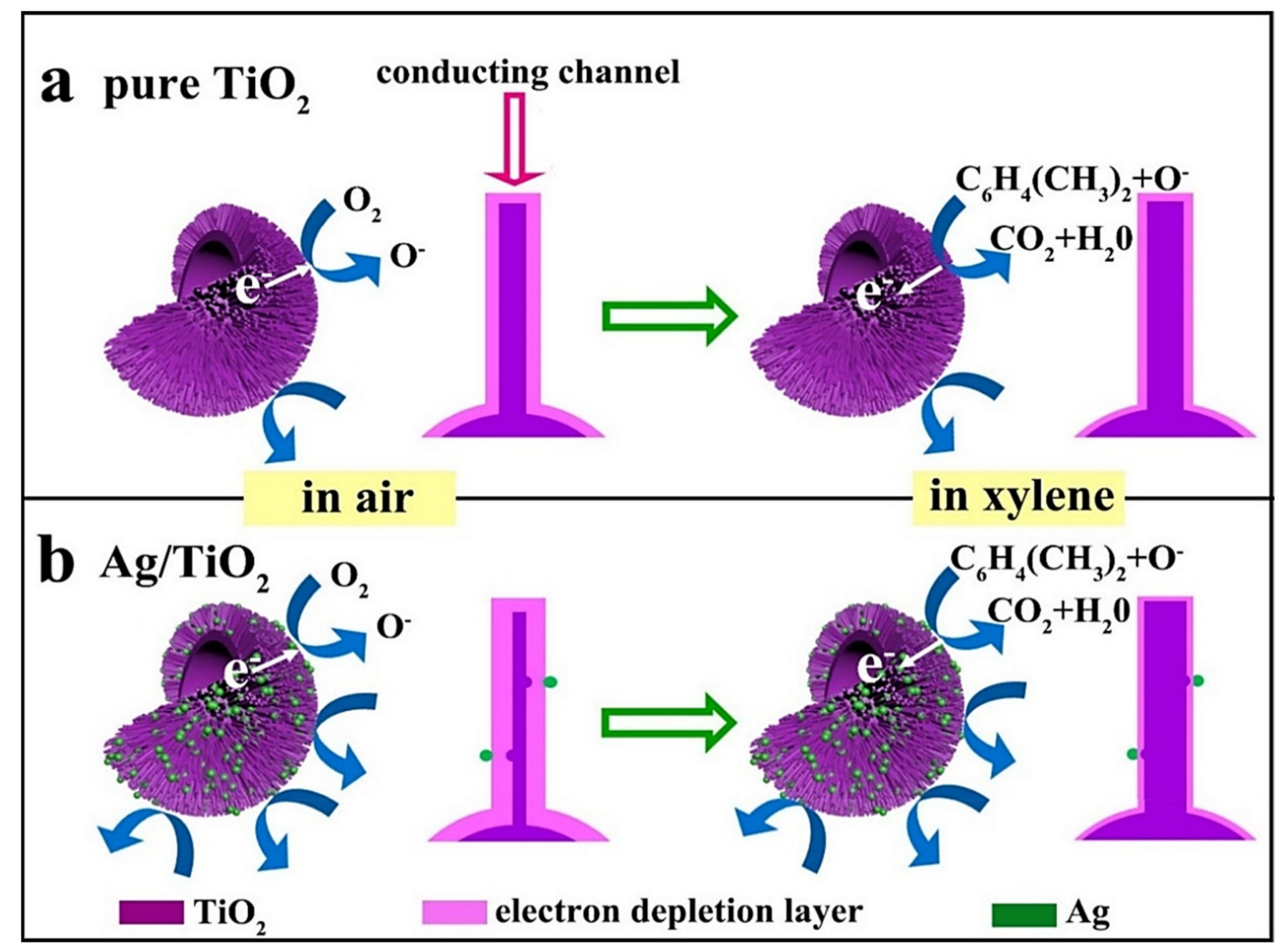

Figure 14. Schematic of the $\mathrm{C}_{8} \mathrm{H}_{10}$ gas-sensing mechanism of (a) the pristine and (b) Ag-loaded $\mathrm{TiO}_{2}$ sensors. Reprinted from reference [80] with permission from Elsevier.

\subsection{Ag-Decorated/Loaded Ammonia $\left(\mathrm{NH}_{3}\right)$ Gas Sensors}

$\mathrm{NH}_{3}$ is a hazardous gas that is colorless and toxic. It has significant applications in various areas such as compound fertilizers, synthetic fibers, and biofuels. Additionally, exposure to $\mathrm{NH}_{3}$ at high levels may result in serious effects, including irritation of the eyes/skin/throat and the respiratory tract, on the human body [81,82]. Karaduman et al. [83] reported the $\mathrm{NH}_{3}$-sensing characteristics of Ag-decorated rGO. In this case, when $\mathrm{NH}_{3}$ gas molecules adsorbed on the surface of rGO by physisorption, the holes of rGO interacted with the electron-donating $\mathrm{NH}_{3}$ gas. Therefore, the degree of delocalization of the conjugated p-electrons of the detecting surface enhanced through the transfer of charge carriers from the adsorbed $\mathrm{NH}_{3}$ molecules. This process reduced the concentrations of charge carriers, thereby increasing the electrical resistance of the sensing material. The enhanced $\mathrm{NH}_{3}$ sensing response of the Ag-loaded $\mathrm{rGO}$ sensor was attributed to the following factors: (i) The functional groups and defects in rGO provided numerous active sites for $\mathrm{NH}_{3}$ adsorption, increasing the gas adsorption capacity. (ii) The existence of $\mathrm{Ag}$ NPs resulted in the adsorption of more $\mathrm{NH}_{3}$ molecules on the $\mathrm{rGO}$ surface as $\mathrm{NH}_{3}$ molecules strongly bound to the rGO surface. The catalytic characteristics of Ag NPs stimulated the breakdown of $\mathrm{NH}_{3}$ into active radicals and enhanced the reaction between chemisorbed $\mathrm{O}$ ions and $\mathrm{NH}_{3}$ molecules. (iii) The development of an n-AgxOy/p-rGO heterointerface led to a depletion region, which concurrently lowered the concentrations of 
carriers on both sides. When the sensor was exposed to $\mathrm{NH}_{3}$ gas, the electronic conductance of the sensor considerably increased, which improved the sensing response.

Organic/inorganic hybrid nanocomposites possess unique characteristics owing to the combined properties of polymers and SMOs. Additionally, decoration with noble metals, including Ag, may enhance the unique characteristics of the hybrid materials because of the catalytic activity of Ag. Qin et al. [84] reported the $\mathrm{NH}_{3}$-sensing properties of Ag-loaded polypyrrole@Si nanowire (Ppy@SiNW) core-shell structures (Figure 15).
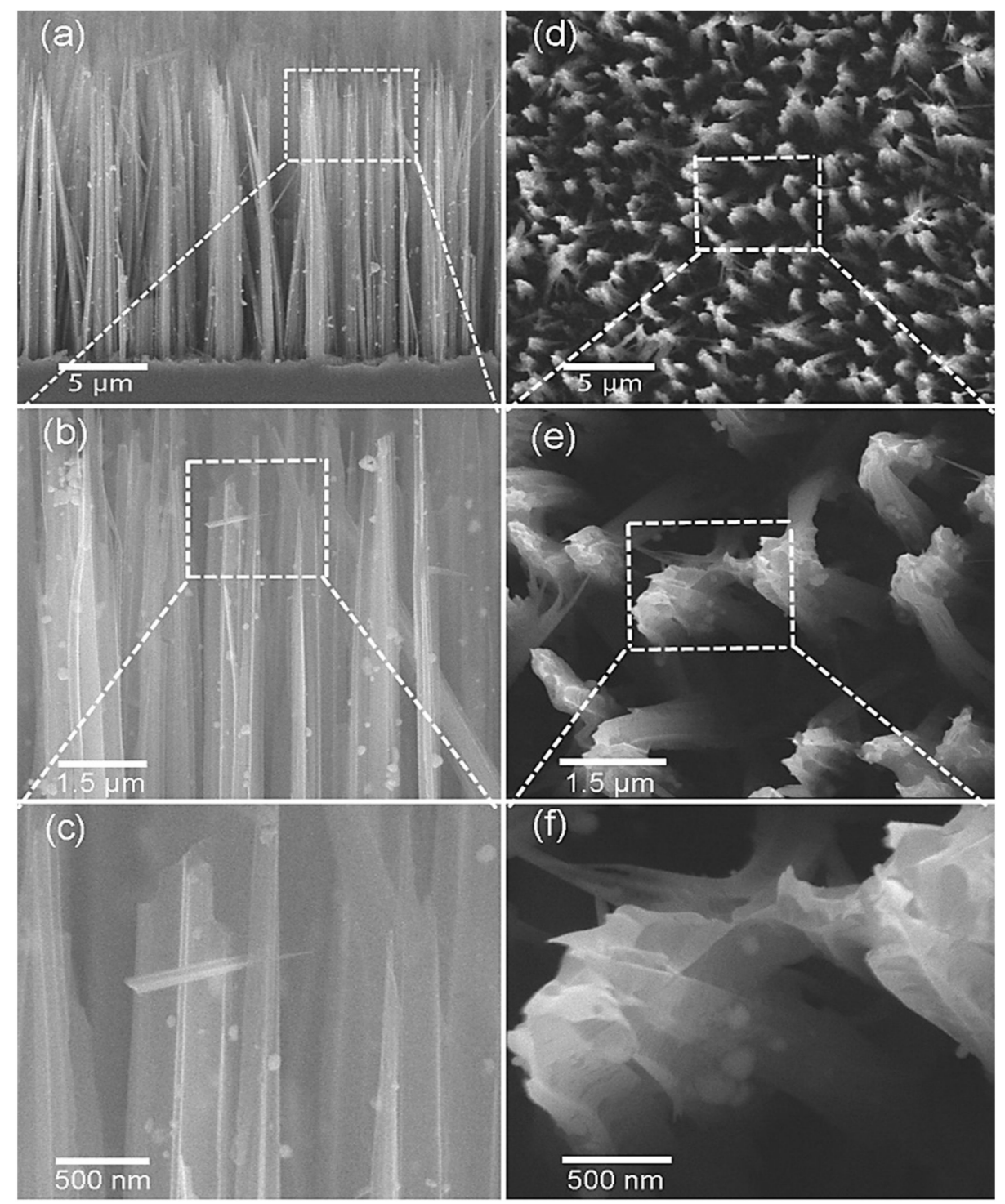

Figure 15. SEM images of Ag-PPy@SiNWs with increasing resolution in front view $(\mathbf{a}-\mathbf{c})$ and planar views (d-f). Reprinted from reference [84] with permission from Elsevier.

Herein, electrical transport occurred in both the shell and the nearby core at the Si/PPy interface because of the thin layer of the PPy shell. Moreover, the Ag-loaded sensor exhibited baseline resistance that was higher than that of the pristine sensor, indicating strong electronic sensitization effect of the Ag NPs. $\mathrm{NH}_{3}$ sensing measurement was conducted using the Ag-loaded PPy@SiNW sensor under high ambient humidity conditions. In this case, a higher $\mathrm{NH}_{3}$ response and weaker humidity interference were noticed following the loading of Ag NPs onto the PPy@SiNW sensor. Actually, the Ag NPs coordinated with -N groups (tertiary $\mathrm{N}$ ) in the organic chains. Note that the tertiary groups of $\mathrm{N}$ are the general coordination sites of the water molecules adsorbed on the polymer surface. Therefore, throughout the polymerization of $\mathrm{PPy}, \mathrm{Ag}^{0}$ preferably coordinated with $-\mathrm{N}$ groups in 
PPy, which inhibited further adsorption of water on similar -N groups. Simultaneously, the loaded Ag NPs were highly hydrophobic. Thus, no significant water adsorption occurred on the surfaces of the Ag NPs, even at $100 \%$ relative humidity. Accordingly, the enhanced anti-humidity interference properties of the Ag-PPy@SiNWs originated from the attenuation of water adsorption on the Ag-loaded PPy shell. The Ag NPs loaded on the PPy chain demonstrated high hydrophobicity (Figure 16), which resulted in nearly no water adsorption on the PPy shells. The minimal adsorption of water molecules was also beneficial for the electronic and chemical effects of Ag NPs. These factors also caused higher response amplitudes at high ambient humidity [84].

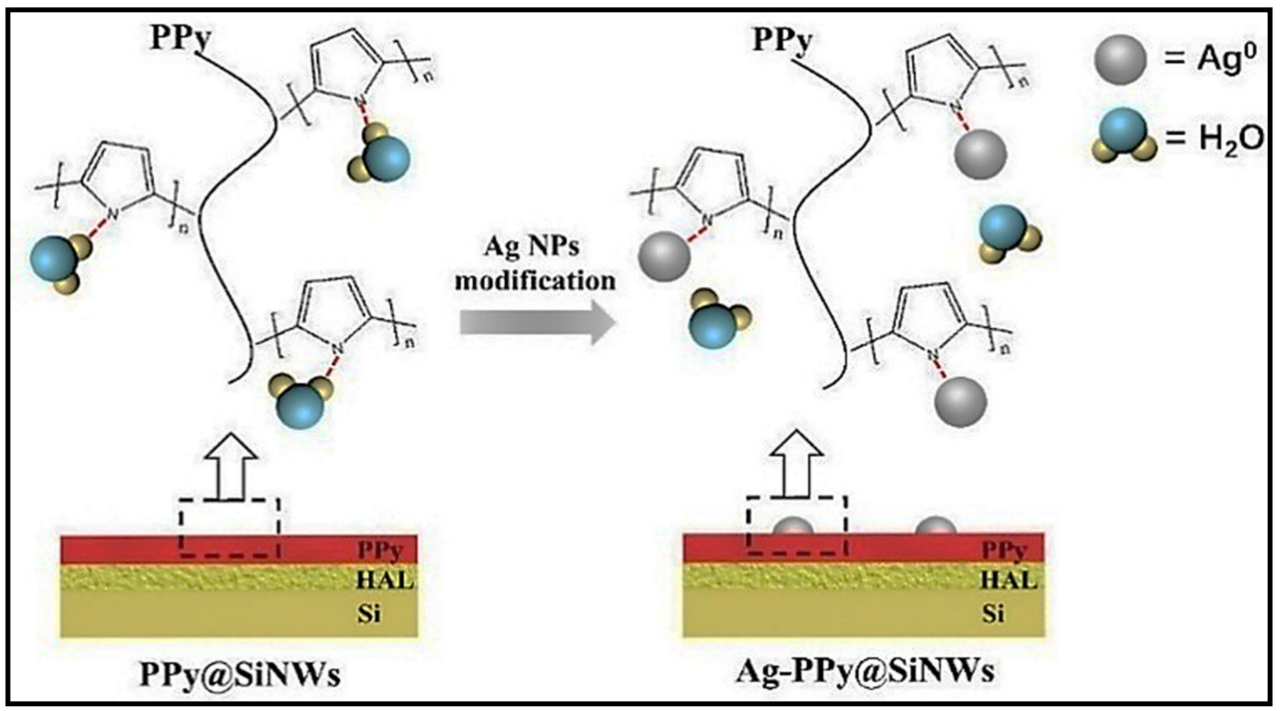

Figure 16. Schematic of the anti-humidity effect caused by Ag NPs. Reprinted from reference [84] with permission from Elsevier.

\subsection{Summary of Ag-Decorated Gas Sensors}

In the above sections, we have described the effect of $\mathrm{Ag}$ decoration on the gas response of resistive-based gas sensors. Table 1 [48-52,54,60,65,66,69,70,72,74,76,77,80,85-95] shows the gas-sensing performances of Ag-loaded SMO-based sensors for various toxic gases. In addition, other researchers [95-109] have reported enhanced gas sensing after Ag decoration. Depending on the type of SMO and the synergistic effects between $\mathrm{Ag}$ and $\mathrm{SMO}$, the sensing temperature can vary from room temperature to high temperatures. Furthermore, in some cases, higher responses were realized after loading Ag NPs onto the surfaces of SMOs. Overall, in the presence of Ag NPs, not only the sensing temperatures reduced but also higher responses were attained when compared with those of the pure gas sensors, and selectivity improved owing to the catalytic activities of the Ag NPs.

Table 1. Gas-sensing properties of Ag-decorated SMO-based gas sensors for different gases.

\begin{tabular}{|c|c|c|c|c|c|}
\hline Sensing Materials & Gas Type & GC (ppm) & $\mathrm{T}\left({ }^{\circ} \mathrm{C}\right)$ & Response & Ref. \\
\hline Ag-loaded $\mathrm{SnO}_{2}$ hollow NFs & $\mathrm{CH}_{3} \mathrm{COCH}_{3}$ & 50 & 160 & 42 & [48] \\
\hline Ag-decorated $\mathrm{TiO}_{2} \mathrm{NRs}$ & $\mathrm{CH}_{3} \mathrm{COCH}_{3}$ & 3.8 & 200 & $7.31(\Delta \mathrm{I}) / \mathrm{I}_{0}$ & [49] \\
\hline Ag-loaded $\mathrm{BiFe}_{2} \mathrm{O}_{4} \mathrm{NPs}$ & $\mathrm{Cl}_{2}$ & 10 & 240 & 72.62 & [50] \\
\hline Ag-decorated $\mathrm{ZnO} / \mathrm{G}$ nanocomposite & $\mathrm{C}_{2} \mathrm{H}_{2}$ & 100 & 150 & 21.2 & [51] \\
\hline 5 wt. $\%$ Ag-loaded ZnO NPs & $\mathrm{C}_{2} \mathrm{H}_{2}$ & 100 & 200 & $\approx 80 \%$ & [52] \\
\hline Ag-loaded ZnO NRs & $\mathrm{C}_{2} \mathrm{H}_{2}$ & 1000 & 200 & 27.2 & [54] \\
\hline Ag-loaded ZnO NPs & TEA & 100 & 183.5 & 6043 & [60] \\
\hline Ag-loaded Porous ZnO NPs & $\mathrm{HCHO}$ & 100 & 240 & 180.4 & [65] \\
\hline Ag-loaded $\mathrm{In}_{2} \mathrm{O}_{3}$ sunflower structure & $\mathrm{HCHO}$ & 20 & 240 & 11.3 & [66] \\
\hline
\end{tabular}


Table 1. Cont.

\begin{tabular}{|c|c|c|c|c|c|}
\hline Sensing Materials & Gas Type & GC (ppm) & $\mathrm{T}\left({ }^{\circ} \mathrm{C}\right)$ & Response & Ref. \\
\hline Ag-loaded $\mathrm{ZnO} / \mathrm{MoS}_{2}$ & $\mathrm{CO}$ & 100 & 25 & 6 & [69] \\
\hline Ag-loaded ZnO NPs & $\mathrm{CO}$ & 100 & 130 & 24.17 & [70] \\
\hline Ag-loaded ZnO NPs & $\mathrm{CH}_{4}$ & 5000 & 200 & 20.15 & [70] \\
\hline $\mathrm{Ag} / \mathrm{g}-\mathrm{CN}$ & $\mathrm{C}_{2} \mathrm{H}_{5} \mathrm{OH}$ & 50 & 40 & 1.3 & [72] \\
\hline Ag-loaded mesoporous $\mathrm{WO}_{3}$ & $\mathrm{NO}_{2}$ & 1 & 75 & 40 & [74] \\
\hline Ag-loaded ZnO NPs & $\mathrm{NO}_{2}$ & 5 & 25 (UV light) & 1.545 & [76] \\
\hline Ag-loaded $\mathrm{Fe}_{2} \mathrm{O}_{3}$ & $\mathrm{CH}_{3} \mathrm{SH}$ & 80 & 25 & $72 \%$ & [77] \\
\hline Ag-loaded $\mathrm{TiO}_{2}$ hedgehog-like architecture & $\mathrm{C}_{8} \mathrm{H}_{10}$ & 100 & 375 & 6.9 & [80] \\
\hline Ag-loaded $\mathrm{SnO}_{2}$ yolk-shell nanostructures & $\mathrm{H}_{2} \mathrm{~S}$ & 5 & 350 & 614.9 & [85] \\
\hline Ag-loaded $\mathrm{ZnO} / \mathrm{rGO}$ & $\mathrm{C}_{2} \mathrm{H}_{2}$ & 1000 & 200 & 33 & [86] \\
\hline Ag-loaded ZnO NRs & $\mathrm{C}_{2} \mathrm{H}_{2}$ & 100 & 250 & 255 & [87] \\
\hline 3.5 wt. $\%$ Ag-decorated $\mathrm{ZnO}$ & $\mathrm{C}_{2} \mathrm{H}_{5} \mathrm{OH}$ & 50 & 325 & 32.5 & [88] \\
\hline Ag-decorated $\mathrm{ZnO} /$ Graphene nanocomposite & $\mathrm{CH}_{3} \mathrm{COCH}_{3}$ & 1000 & 175 & 71 & [89] \\
\hline Ag-loaded 3D porous flower-like ZnO NPs & $\mathrm{C}_{2} \mathrm{H}_{5} \mathrm{OH}$ & 200 & 300 & 268 & [90] \\
\hline Ag-loaded $\operatorname{In}_{2} \mathrm{O}_{3} \mathrm{NPs}$ & $\mathrm{HCHO}$ & 50 & 210 & 156.9 & [91] \\
\hline Ag-loaded $\mathrm{SnO}_{2}$-rGO nanocomposite & $\mathrm{C}_{2} \mathrm{H}_{2}$ & 500 & 90 & $26(\%)$ & [92] \\
\hline Ag-loaded $\mathrm{LaFeO}_{3} \mathrm{NPs}$ & $\mathrm{C}_{7} \mathrm{H}_{8}$ & 5 & 215 & 24 & [93] \\
\hline Ag-loaded $\mathrm{MoO}_{3}$ nanobelts & TEA & 100 & 240 & 26.58 & [94] \\
\hline $\mathrm{Ag}$-decorated $\mathrm{TiO}_{2} \mathrm{QDs}$ & $\mathrm{NH}_{3}$ & 20 & 25 & 25.1 & [95] \\
\hline
\end{tabular}

$\mathrm{T}=$ operating temperature of the sensor, $\mathrm{GC}=$ gas concentration, and $\mathrm{ppm}=$ parts per million .

\section{Ag-Doped Gas Sensors}

Doped metal oxide is the structure where additives are incorporated in the lattice of host material, as shown in Figure 17a [110], and it can affect the gas response of the doped gas sensor (Figure 17b). In gas-sensing studies, very less attention has been devoted to $\mathrm{Ag}$ doping than to Ag loading.

(a)

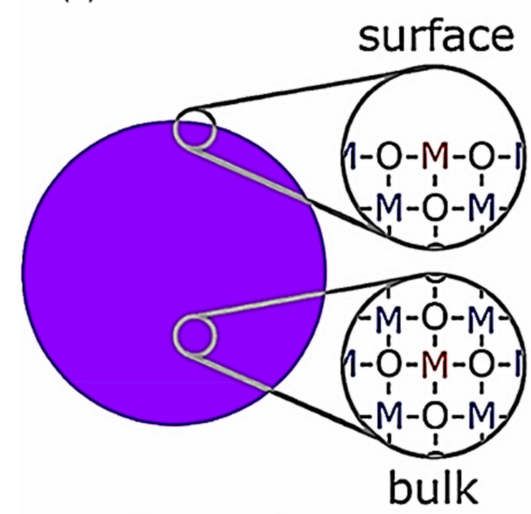

(b)

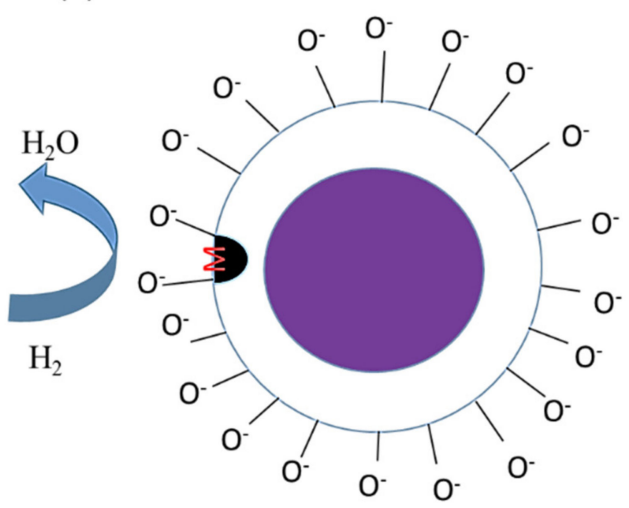

Figure 17. (a) Doping of a metal on metal oxide and (b) doping effect on the gas interaction with the sensing layer. Reprinted from reference [110] with permission from ACS.

$\mathrm{Ag}$ doping is often performed by incorporating $\mathrm{Ag}$ atoms into the SMO lattice. When $\mathrm{Ag}$ atoms are homogeneously dispersed in the semiconductor lattice, mobile charge carriers are generated, thereby changing the electrical properties of the gas sensor [111]. An overview of some Ag-doped gas sensors is presented in this section. 
Hydrogen sulfide $\left(\mathrm{H}_{2} \mathrm{~S}\right)$ is a highly toxic gas that is typically produced by the oil industry, natural gas plants, and sewage plants. Exposure to $\mathrm{H}_{2} \mathrm{~S}$ at higher levels (namely, $100 \mathrm{ppm}$ ) may cause sudden collapse with respiratory loss, and the possibility of fatality is very high [112].

Ovsianytskyi et al. [113] developed a $\mathrm{H}_{2} \mathrm{~S}$ gas sensor using Ag NP-doped graphene. When the Ag-doped graphene sensor was exposed to $\mathrm{H}_{2} \mathrm{~S}$ gas, $\mathrm{H}_{2} \mathrm{~S}$ adsorbed on $\mathrm{Ag}$ rather than on $\mathrm{C}$ because $\mathrm{Ag}$ is less electronegative than $\mathrm{C}$; the adsorption of $\mathrm{H}_{2} \mathrm{~S}$ led to a possible dissociation of $\mathrm{H}_{2} \mathrm{~S}$, and accordingly, $\mathrm{SO}_{2}$ and $\mathrm{H}_{2} \mathrm{O}$ were formed by the release of electrons (Figure 18). The released electrons entered graphene and recombined with intrinsic holes. This process decreased the concentrations of charge carriers and increased the resistance of Ag-doped graphene. Furthermore, Kolhe et al. [114] prepared $\mathrm{SnO}_{2}$ thin films doped with 1.5, 3.0, and $4.5 \mathrm{~mol} \% \mathrm{Ag}$ by chemical spray pyrolysis for application in $\mathrm{H}_{2} \mathrm{~S}$ sensors. Herein, the 3.0 mol.\% Ag-doped $\mathrm{SnO}_{2}$ sensor exhibited the maximum $\mathrm{H}_{2} \mathrm{~S}$ response. The enhanced response of $\mathrm{SnO}_{2}$ thin films toward $\mathrm{H}_{2} \mathrm{~S}$ gas upon Ag doping was related to the catalytic activity of $\mathrm{Ag}$ or $\mathrm{Ag}_{2} \mathrm{O}$ and the formation of heterojunctions between $\mathrm{Ag} / \mathrm{SnO}_{2}$ and $\mathrm{Ag}_{2} \mathrm{O} / \mathrm{SnO}_{2}$. When the doping concentration of $\mathrm{Ag}$ was excessively high, the sensor response decreased because of the decrease in the number of dynamic sites owing to the accumulation of Ag grains. Additionally, Anand et al. [115] synthesized $\mathrm{In}_{2} \mathrm{O}_{3}$ and Ag-doped $\operatorname{In}_{2} \mathrm{O}_{3}$ NPs using a simple coprecipitation technique and utilized them for the detection of $\mathrm{C}_{2} \mathrm{H}_{5} \mathrm{OH}$. Ag doping induced defects and vacancies in $\operatorname{In}_{2} \mathrm{O}_{3}$, which improved the number of dynamic sites on the sensor surface and accordingly increased the adsorption of $\mathrm{C}_{2} \mathrm{H}_{5} \mathrm{OH}$. Consequently, the width of the depletion layer expanded, and thus, the resistance of the Ag-doped $\operatorname{In}_{2} \mathrm{O}_{3}$ sensor considerably increased. When the sensor was exposed to $\mathrm{C}_{2} \mathrm{H}_{5} \mathrm{OH}$ gas, the width of the depletion layer substantially reduced, which was a contributing factor to the sensing signal. Moreover, $\mathrm{Ag}$ acted as a catalyst and facilitated the sensor response by forming activated species of the chemisorbed oxygen ions, which were subsequently released to the $\operatorname{In}_{2} \mathrm{O}_{3}$ surface and caused the $\mathrm{C}_{2} \mathrm{H}_{5} \mathrm{OH}$ molecules to rapidly react with the chemisorbed oxygen ions.

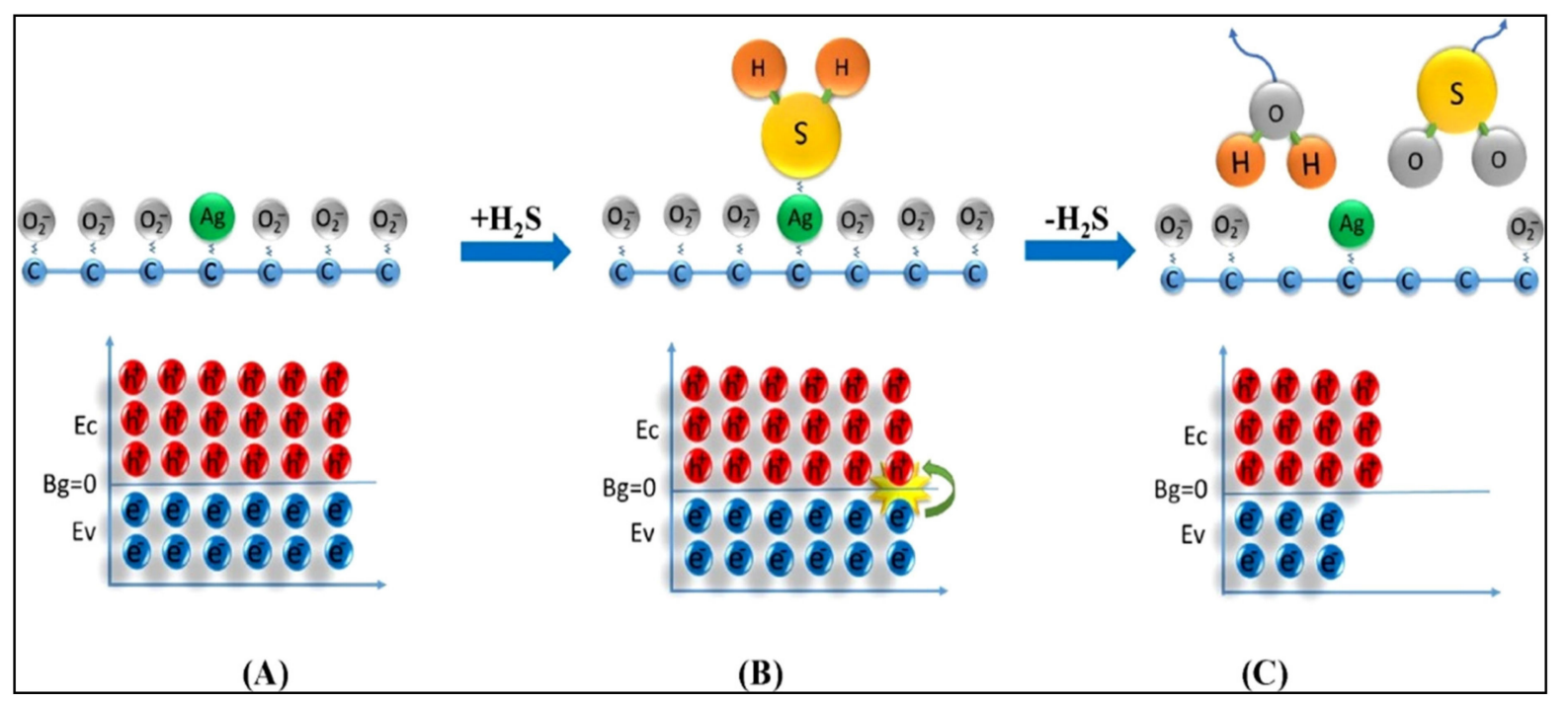

Figure 18. Schematic of $\mathrm{H}_{2} \mathrm{~S}$ sensing by Ag-doped graphene. Energy diagram of (A) Ag-doped graphene, (B) interaction of Ag-doped graphene with $\mathrm{H}_{2} \mathrm{~S}$ gas, and $(\mathbf{C})$ the formation of $\mathrm{SO}_{2}$ and $\mathrm{H}_{2} \mathrm{O}$. Reprinted from reference [113] with permission from Elsevier.

Finally, Ding et al. [116] prepared 0.5, 1.0, and 3.0 mol.\% Ag-doped hollow urchin-like $\mathrm{In}_{2} \mathrm{O}_{3}$ spheres via a one-step hydrothermal method for application in $\mathrm{NO}_{2}$ sensors. Herein, the sensor fabricated using $1.0 \mathrm{~mol} . \% \mathrm{Ag}$ demonstrated the maximum response to $\mathrm{NO}_{2}$ gas at an operating temperature of $62{ }^{\circ} \mathrm{C}$. An excellent response of 190 was obtained to 1 ppm $\mathrm{NO}_{2}$ gas at $62{ }^{\circ} \mathrm{C}$, which was almost 23 times that of the pristine $\mathrm{In}_{2} \mathrm{O}_{3}$ sensor. 
The improvement in the $\mathrm{NO}_{2}$ sensing response of the $\operatorname{In}_{2} \mathrm{O}_{3}$ sensor after $\mathrm{Ag}$ doping was ascribed to the chemical sensitization effect of $\mathrm{Ag}$, which acted as a dynamic catalyst and produced more active sites on the sensor surface. The generated active sites caused the direct adsorption of $\mathrm{NO}_{2}$, which finally led to a higher $\mathrm{NO}_{2}$ response. When the Ag doping concentration was low, the catalytic effect was inadequate to make the entire surface of the sensor available for the adsorption of $\mathrm{NO}_{2}$ gas. Nevertheless, when $3.0 \mathrm{~mol} \% \mathrm{Ag}$ was doped, the sensor response decreased. Ag at higher doping concentrations covered the active sites on the sensor surface, which prevented the sensor from responding to the $\mathrm{NO}_{2}$ gas. Furthermore, the surface area of the optimal sensor was $100.6 \mathrm{~m}^{2} / \mathrm{g}$, which also contributed to the improved gas response.

Table 2 presents the sensing properties of Ag-doped SMO-based gas-sensing devices [92-107]. Different gases at various temperatures can be detected by doping Ag into the pristine sensing device, which suggests the promising role of $\mathrm{Ag}$ as a noble metal dopant in the detection of toxic gases.

Table 2. Gas-sensing properties of Ag-doped SMO-based gas sensors.

\begin{tabular}{|c|c|c|c|c|c|}
\hline Sensing Materials & Gas Type & GC (ppm) & $\mathrm{T}\left({ }^{\circ} \mathrm{C}\right)$ & Response & Ref. \\
\hline Ag-doped graphene & $\mathrm{H}_{2} \mathrm{~S}$ & 50 & 25 & $140 \%$ & [113] \\
\hline Ag-doped $\mathrm{SnO}_{2}$ & $\mathrm{H}_{2} \mathrm{~S}$ & 450 & 200 & 1.32 & [114] \\
\hline $3 \%$ Ag-doped $\operatorname{In}_{2} \mathrm{O}_{3}$ & $\mathrm{C}_{2} \mathrm{H}_{5} \mathrm{OH}$ & 1000 & 300 & 175 & [115] \\
\hline Ag-doped $\operatorname{In}_{2} \mathrm{O}_{3}$ NPs & $\mathrm{NO}_{2}$ & 1 & 62 & 190.1 & [116] \\
\hline Ag-doped $\mathrm{ZnO}$ nanoneedles & $\mathrm{CH}_{3} \mathrm{COCH}_{3}$ & 100 & 370 & 19 & [117] \\
\hline Ag-doped $\mathrm{ZnO}$ nanoellipsoids & $\mathrm{CH}_{3} \mathrm{OH}$ & 200 & 370 & 15.8 & [118] \\
\hline Ag-doped $\mathrm{LaFeO}_{3} \mathrm{NPs}$ & $\mathrm{HCHO}$ & 100 & 230 & 20 & [119] \\
\hline Ag-doped $\mathrm{Fe}_{2} \mathrm{O}_{3}$ NPs & $\mathrm{H}_{2} \mathrm{~S}$ & 100 & 400 & 220 & [120] \\
\hline Ag-doped $\mathrm{CaCu}_{3} \mathrm{Ti}_{4} \mathrm{O}_{12} \mathrm{NPs}$ & $\mathrm{H}_{2} \mathrm{~S}$ & 10 & 250 & 110 & [121] \\
\hline Ag-doped $\mathrm{In}_{2} \mathrm{O}_{3}$ NPs & $\mathrm{C}_{2} \mathrm{H}_{5} \mathrm{OH}$ & 150 & 100 & 100 & [122] \\
\hline Ag-doped $\mathrm{Zn}_{2} \mathrm{SnO}_{4} / \mathrm{SnO}_{2}$ hollow NPs & $\mathrm{HCHO}$ & 140 & 50 & 62.2 & [123] \\
\hline Ag-doped $\mathrm{SnO}_{2} \mathrm{NPs}$ & $\mathrm{H}_{2}$ & 50 & 300 & 25 & [124] \\
\hline Ag-doped ZnO NWs & $\mathrm{C}_{2} \mathrm{H}_{5} \mathrm{OH}$ & 1 & 300 & $203 \%$ & [125] \\
\hline Ag-doped $\mathrm{In}_{2} \mathrm{O}_{3} \mathrm{NFs}$ & $\mathrm{HCHO}$ & 600 & 120 & 130 & [126] \\
\hline Ag-doped $\mathrm{WO}_{3}$ & $\mathrm{C}_{2} \mathrm{H}_{5} \mathrm{OH}$ & 100 & 300 & 65 & [127] \\
\hline Ag-decorated/Ag-doped $\mathrm{ZnO}$ columnar films & $\mathrm{C}_{2} \mathrm{H}_{5} \mathrm{OH}$ & 100 & 250 & 145 & [128] \\
\hline
\end{tabular}

$\mathrm{T}=$ operating temperature of the sensor, $\mathrm{GC}=$ gas concentration, and $\mathrm{ppm}=$ parts per million.

\section{Conclusions and Perspectives}

In this review, we have examined the promising effects of Ag addition on the detection performances of chemiresistive gas sensors. This review demonstrated that several toxic gases and VOCs can be efficiently detected by introducing Ag into SMOs and corresponding composite-based chemiresistive sensors. The gas-sensing performances of chemiresistive sensors, such as SMOs and related composites, can be enhanced by Ag doping owing to the catalytic activity and electronic/chemical sensitization effects of Ag. As an effective catalyst, $\mathrm{Ag}$ can attract abundant $\mathrm{O}_{2}$ molecules from the air and transfer them to the surfaces of SMOs, accordingly promoting the capture of electrons from SMOs by $\mathrm{O}_{2}$ molecules. Moreover, the higher electrical conductivity of Ag NPs facilitated rapid electron transfer and thereby improved the sensor response. Therefore, Ag may be an excellent choice as a sensitizer to improve the sensing performances of chemiresistive sensors as it offers additional active adsorption sites and charge transfer pathways to enhance surface reactions. Generally, the introduction of $\mathrm{Ag}$ in an optimal amount into the sensing material can lead to the best sensing properties, and a bell-shaped relationship typically exists 
between the sensor response and the addition amount of Ag [129]. Due to the low cost of Ag than that of other noble metals, the incorporation of Ag into gas sensors is a highly promising strategy to not only reduce the overall price of these sensors but also enhance their sensing properties.

Although different approaches have been introduced for the synthesis of Ag-based chemiresistive sensors, prospects for the development of Ag-based chemiresistive sensors are still considerable. Nevertheless, to date, the effect of Ag particle size on the gas sensor response has not been systematically investigated, and it should be realized in future efforts related to the decoration of $\mathrm{Ag}$ on the surfaces of SMOs and related composites. Additionally, the effects of annealing temperature on the final responses of Ag-decorated gas sensors have not been examined to date, and it may constitute another exciting area of research. In fact, less efforts have been dedicated toward studying Ag doping than those toward studying Ag decoration on the surfaces of SMOs for the detection of gases. Particularly, further Ag doping studies should be conducted in the future. Furthermore, selectivity toward a target gas remains a major concern for Ag-based SMOs and related composite-based resistive gas sensors. Additionally, most of the reported Ag-based chemiresistive sensors operate at higher temperatures, which hinders their commercialization. Therefore, the development of novel functional nanomaterials with superior characteristics is required to address this issue. Efforts should be made to develop room-temperature sensors to reduce energy consumption with enhanced sensitivity. For example, UV irradiation [130], bimetallic decoration [131], use of quantum dots [132] or their combinations [133] are among different strategies that can reduce the sensing temperature even to room temperature. In addition, a fluctuation-enhanced sensing (FSA) approach can be used to improve the sensitivity of the sensors [134-137].

Moreover, understanding the plausible detection mechanism of a specific target gas is a challenge in the field of chemiresistive sensors. Thus, to gain a deeper understanding of the basic sensing principles and respective surface adsorption/desorption kinetics between the target gas and sensing materials, appropriate technology or reasonable models need to be established. More importantly, all reported Ag-based chemiresistive sensors are laboratorymade and probably contain instrumental errors. Thus, further studies are necessary to enhance the robustness of the data, and the respective efforts must be dedicated to the commercialization of these devices in practice.

Author Contributions: Conceptualization, A.M., H.W.K. and S.S.K.; writing-original draft preparation, A.M., M.S. and S.N.; writing—review and editing, A.M., M.S. and S.N.; supervision, H.W.K. and S.S.K.; funding acquisition, H.W.K. and S.S.K. All authors have read and agreed to the published version of the manuscript.

Funding: This research was supported by the PAP program (year: 2021) of the Korea Polar Research Institute and a National Research Foundation of Korea (NRF) grant funded by the Korean government (MSIT) (No. 2021R1A2C1009790).

Institutional Review Board Statement: Not applicable.

Informed Consent Statement: Not applicable.

Data Availability Statement: Not applicable.

Conflicts of Interest: The authors declare no conflict of interest.

\section{References}

1. Song, R.; Wang, Z.; Zhou, X.; Huang, L.; Chi, L. Gas-sensing performance and operation mechanism of organic $\pi$-conjugated materials. ChemPlusChem 2019, 84, 1222-1234. [CrossRef] [PubMed]

2. Li, H.; Shi, W.; Song, J.; Jang, H.J.; Dailey, J.; Yu, J.; Katz, H.E. Chemical and biomolecule sensing with organic field-effect transistors. Chem. Rev. 2018, 119, 3-35. [CrossRef]

3. Ali, S.; Gupta, A.; Shafiei, M.; Langford, S.J. Recent advances in perylene diimide-based active materials in electrical mode gas sensing. Chemosensors 2021, 9, 30. [CrossRef] 
4. Vajhadin, F.; Mazloum-Ardakani, M.; Amini, A. Metal oxide-based gas sensors for the detection of exhaled breath markers. Med. Devices Sens. 2021, 4, e10161. [CrossRef]

5. Wang, Y.; Duan, L.; Deng, Z.; Liao, J. Electrically transduced gas sensors based on semiconducting metal oxide nanowires. Sensors 2020, 20, 6781. [CrossRef]

6. Chowdhury, N.K.; Bhowmik, B. Micro/nanostructured gas sensors: The physics behind the nanostructure growth, sensing and selectivity mechanisms. Nanoscale Adv. 2021, 3, 73-93. [CrossRef]

7. Majhi, S.M.; Mirzaei, A.; Navale, S.; Kim, H.W.; Kim, S.S. Boosting the sensing properties of resistive-based gas sensors by irradiation techniques: A review. Nanoscale 2021, 13, 4728-4757. [CrossRef] [PubMed]

8. Wang, C.; Yin, L.; Zhang, L.; Xiang, D.; Gao, R. Metal oxide gas sensors: Sensitivity and influencing factors. Sensors 2010, 10, 2088-2106. [CrossRef] [PubMed]

9. Godse, P.R.; Mane, A.T.; Navale, Y.H.; Navale, S.T.; Mulik, R.N.; Patil, V.B. Hydrothermally grown 1D ZnO nanostructures for rapid detection of $\mathrm{NO}_{2}$ gas. SN Appl. Sci. 2021, 3, 360. [CrossRef]

10. Ji, H.; Zeng, W.; Li, Y. Gas sensing mechanisms of metal oxide semiconductors: A focus review. Nanoscale 2019, 11, 22664-22684. [CrossRef]

11. Navale, S.T.; Yang, Z.B.; Liu, C.; Cao, P.J.; Patil, V.B.; Ramgir, N.S.; Mane, R.S.; Stadler, F.J. Enhanced acetone sensing properties of titanium dioxide nanoparticles with a sub-ppm detection limit. Sens. Actuators B Chem. 2018, 255, 1701-1710. [CrossRef]

12. Lin, T.; Lv, X.; Hu, Z.; Xu, A.; Feng, C. Semiconductor metal oxides as chemoresistive sensors for detecting volatile organic compounds. Sensors 2019, 19, 233. [CrossRef] [PubMed]

13. Cao, P.; Gui, X.; Navale, S.; Han, S.; Xu, W.; Fang, M.; Liu, X.; Zeng, Y.X.; Liu, W.; Zhu, D.; et al. Design of flower-like $\mathrm{V}_{2} \mathrm{O}_{5}$ hierarchical nanostructures by hydrothermal strategy for the selective and sensitive detection of xylene. J. Alloy. Compd. 2020, 815, 152378. [CrossRef]

14. Bhati, V.S.; Kumar, M.; Banerjee, R. Gas sensing performance of 2D nanomaterials/metal oxide nanocomposites: A review. J. Mater. Chem. C 2021, 9, 8776-8808. [CrossRef]

15. Meng, F.; Hou, N.; Jin, Z.; Sun, B.; Guo, Z.; Kong, L.; Xiao, X.; Wu, H.; Li, M.; Liu, J. Ag-decorated ultra-thin porous singlecrystalline $\mathrm{ZnO}$ nanosheets prepared by sunlight induced solvent reduction and their highly sensitive detection of ethanol. Sens. Actuators B Chem. 2015, 209, 975-982. [CrossRef]

16. Pandey, S.; Goswami, G.K.; Nanda, K.K. Nanocomposite based flexible ultrasensitive resistive gas sensor for chemical reactions studies. Sci. Rep. 2013, 3, 1-6. [CrossRef]

17. Jimenez-Cadena, G.; Riu, J.; Rius, F.X. Gas sensors based on nanostructured materials. Analyst 2007, 132, 1083-1099. [CrossRef]

18. Chen, L.; Tsang, S.C. Ag doped $\mathrm{WO}_{3}$-based powder sensor for the detection of $\mathrm{NO}$ gas in air. Sens. Actuators B Chem. 2003, 89, 68-75. [CrossRef]

19. Kim, H.J.; Lee, J.H. Highly sensitive and selective gas sensors using p-type oxide semiconductors: Overview. Sens. Actuators $B$ Chem. 2014, 192, 607-627. [CrossRef]

20. Kwon, Y.J.; Kang, S.Y.; Mirzaei, A.; Choi, M.S.; Bang, J.H.; Kim, S.S.; Kim, H.W. Enhancement of gas sensing properties by the functionalization of $\mathrm{ZnO}$-branched $\mathrm{SnO}_{2}$ nanowires with $\mathrm{Cr}_{2} \mathrm{O}_{3}$ nanoparticles. Sens. Actuators B Chem. 2017, 249, 656-666. [CrossRef]

21. Kim, H.-J.; Yoon, J.-W.; Choi, K.-I.; Jang, H.W.; Umar, A.; Lee, J.-H. Ultraselective and sensitive detection of xylene and toluene for monitoring indoor air pollution using $\mathrm{Cr}$-doped $\mathrm{NiO}$ hierarchical nanostructures. Nanoscale 2013, 5, 7066-7073. [CrossRef]

22. Annanouch, F.E.; Haddi, Z.; Ling, M.; Maggio, F.D.; Vallejos, S.; Vilic, T.; Zhu, Y.; Shujah, T.; Umek, P.; Bittencourt, C.; et al. Aerosol-assisted CVD-grown PdO nanoparticle decorated tungsten oxide nanoneedles extremely sensitive and selective to hydrogen. ACS Appl. Mater. Inter. 2016, 8, 10413-10421. [CrossRef]

23. Mirzaei, A.; Bang, J.H.; Kim, S.S.; Kim, H.W. Effect of noble metals on hydrogen sensing properties of metal oxide-based gas sensors. J. Sens. Sci. Tech. 2020, 29, 365-368.

24. Miller, D.R.; Akbar, S.A.; Morris, P.A. Nanoscale metal oxide-based heterojunctions for gas sensing: A review. Sens. Actuators B Chem. 2014, 204, 250-272. [CrossRef]

25. Korotcenkov, G.; Cho, B.K. Engineering approaches for the improvement of conductometric gas sensor parameters: Part 1. Improvement of sensor sensitivity and selectivity (short survey). Sens. Actuators B Chem. 2013, 188, 709-728. [CrossRef]

26. Rzaij, J.M.; Abass, A.M. Review on: $\mathrm{TiO}_{2}$ thin film as a metal oxide gas sensor. J. Chem. Rev. 2020, 2, 114-121. [CrossRef]

27. Tian, X.; Cui, X.; Lai, T.; Ren, J.; Yang, Z.; Xiao, M.; Wang, B.; Xiao, X.; Wang, Y. Gas sensors based on TiO ${ }_{2}$ nanostructured materials for the detection of hazardous gases: A review. Nano Mater. Sci. 2021. [CrossRef]

28. Dong, C.; Zhao, R.; Yao, L.; Ran, Y.; Zhang, X.; Wang, Y. A review on $\mathrm{WO}_{3}$ based gas sensors: Morphology control and enhanced sensing properties. J. Alloy. Compd. 2020, 820, 153194. [CrossRef]

29. Hariharan, V.; Gnanavel, B.; Sathiyapriya, R.; Aroulmoji, V. A review on tungsten oxide $\left(\mathrm{WO}_{3}\right)$ and their derivatives for sensor applications. Int. J. Adv. Sci. Eng. 2019, 5, 1163-1168. [CrossRef]

30. Majhi, S.M.; Mirzaei, A.; Kim, H.W.; Kim, S.S.; Kim, T.W. Recent advances in energy-saving chemiresistive gas sensors: A review. Nano Energy 2020, 79, 105369. [CrossRef] [PubMed]

31. Abideen, Z.U.; Kim, J.H.; Lee, J.H.; Kim, J.Y.; Mirzaei, A.; Kim, H.W.; Kim, S.S. Electrospun metal oxide composite nanofibers gas sensors: A review. J. Korean Ceram. Soc. 2017, 54, 366-379. [CrossRef] 
32. Amiri, V.; Roshan, H.; Mirzaei, A.; Sheikhi, M.H. A review of nanostructured resistive-based vanadium oxide gas sensors. Chemosensors 2020, 8, 105. [CrossRef]

33. Al-Hashem, M.; Akbar, S.; Morris, P. Role of oxygen vacancies in nanostructured metal-oxide gas sensors: A review. Sens. Actuators B Chem. 2019, 301, 126845. [CrossRef]

34. Dey, A. Semiconductor metal oxide gas sensors: A review. Mater. Sci. Eng. B 2018, 229, 206-217. [CrossRef]

35. Das, S.; Jayaraman, V. $\mathrm{SnO}_{2}$ : A comprehensive review on structures and gas sensors. Prog. Mater. Sci. 2014, 66, 112-255. [CrossRef]

36. Mirzaei, A.; Yousefi, H.R.; Falsafi, F.; Bonyani, M.; Lee, J.H.; Kim, J.H.; Kim, H.W.; Kim, S.S. An overview on how Pd on resistive-based nanomaterial gas sensors can enhance response toward hydrogen gas. Int. J. Hydrog. Energy 2019, 44, $20552-20571$. [CrossRef]

37. Korotcenkov, G.; Brinzari, V.; Cho, B.K. Conductometric gas sensors based on metal oxides modified with gold nanoparticles: A review. Microchim. Acta 2016, 183, 1033-1054. [CrossRef]

38. Luo, Y.; Zhang, C.; Zheng, B.; Geng, X.; Debliquy, M. Hydrogen sensors based on noble metal doped metal-oxide semiconductor: A review. Int. J. Hydrog. Energy 2017, 42, 20386-20397. [CrossRef]

39. Cattabiani, N.; Baratto, C.; Zappa, D.; Comini, E.; Donarelli, M.; Ferroni, M.; Ponzoni, A.; Faglia, G. Tin oxide nanowires decorated with Ag nanoparticles for visible light-enhanced hydrogen sensing at room temperature: Bridging conductometric gas sensing and plasmon-driven catalysis. J. Phys. Chem. C 2018, 122, 5026-5031. [CrossRef]

40. Conner, W.C., Jr.; Falconer, J.L. Spillover in heterogeneous catalysis. Chem. Rev. 1995, 95, 759-788. [CrossRef]

41. Yamazoe, N. New approaches for improving semiconductor gas sensors. Sens. Actuators B Chem. 1991, 5, 7-19. [CrossRef]

42. Li, Z.; Yao, Z.; Haidry, A.A.; Plecenik, T.; Xie, L.; Sun, L.; Fatima, Q. Resistive-type hydrogen gas sensor based on TiO 2 : A review. Inter. J. Hydrog. Energy 2018, 43, 21114-21132. [CrossRef]

43. Barbosa, M.S.; Suman, P.H.; Kim, J.J.; Tuller, H.L.; Orlandi, O.L. Investigation of electronic and chemical sensitization effects promoted by Pt and Pd nanoparticles on single crystalline SnO nanobelt-based gas sensors. Sens. Actuators B Chem. 2019, 301, 127055. [CrossRef]

44. Molavi, R.; Sheikhi, M.H. Low temperature carbon monoxide gas sensor based on $\mathrm{Ag}-\mathrm{Co}_{3} \mathrm{O}_{4}$ thick film nanocomposite. Mater. Lett. 2018, 233, 74-77. [CrossRef]

45. Li, M.; Zhu, H.; Wang, B.; Cheng, J.; Yan, W.; Xia, S.; Tang, Z. Ultrasensitive and highly selective detection of methoxy propanol based on Ag-decorated $\mathrm{SnO}_{2}$ hollow nanospheres. Sens. Actuators B Chem. 2016, 232, 545-556. [CrossRef]

46. Korotcenkov, G. Gas response control through structural and chemical modification of metal oxide films: State of the art and approaches. Sens. Actuators B Chem. 2005, 107, 209-232. [CrossRef]

47. Amiri, V.; Roshan, H.; Mirzaei, A.; Neri, G.; Ayesh, A.I. Nanostructured metal oxide-based acetone gas sensors: A review. Sensors 2020, 20, 3096. [CrossRef]

48. Xu, X.; Chen, Y.; Zhang, G.; Ma, S.; Lu, Y.; Bian, H.; Chen, Q. Highly sensitive VOCs-acetone sensor based on Ag-decorated SnO 2 hollow nanofibers. J. Alloy. Compd. 2017, 703, 572-579. [CrossRef]

49. Kılıç, A.; Alev, O.; Özdemir, O.; Arslan, L.Ç.; Büyükköse, S.; Öztürk, Z.Z. The effect of Ag loading on gas sensor properties of $\mathrm{TiO}_{2}$ nanorods. Thin Solid Film. 2021, 726, 138662. [CrossRef]

50. Li, Q.; Zhang, W.; Wang, C.; Ma, J.; Ning, L.; Fan, H. Ag modified bismuth ferrite nanospheres as a chlorine gas sensor. RSC Adv. 2018, 8, 33156-33163. [CrossRef]

51. Iftekhar Uddin, A.S.M.; Phan, D.-T.; Chung, G.-S. Low temperature acetylene gas sensor based on Ag nanoparticles-loaded ZnO-reduced graphene oxide hybrid. Sens. Actuators B Chem. 2015, 207, 362-369. [CrossRef]

52. Lee, K.-W.; Uddin, A.S.M.I.; Phan, D.-T.; Chung, G.-S. Fabrication of low-temperature acetylene gas sensor based on Ag nanoparticles-loaded hierarchical $\mathrm{ZnO}$ nanostructures. Electron. Lett. 2014, 51, 572-574. [CrossRef]

53. Gupta Chatterjee, S.; Chatterjee, S.; Ray, A.K.; Chakraborty, A.K. Graphene-metal oxide nanohybrids for toxic gas sensor: A review. Sens. Actuators B Chem. 2015, 221, 1170-1181. [CrossRef]

54. Uddin, A.S.M.I.; Yaqoob, U.; Phan, D.-T.; Chung, G.-S. A novel flexible acetylene gas sensor based on PI/PTFE-supported Ag-loaded vertical ZnO nanorods array. Sens. Actuators B Chem. 2015, 222, 536-543. [CrossRef]

55. Espinosa, E.H.; Ionescu, R.; Bittencourt, C.; Felten, A.; Erni, R.; Van Tendeloo, G.; Pireaux, J.J.; Llobet, E. Metal-decorated multi-wall carbon nanotubes for low temperature gas sensing. Thin Solid Film. 2007, 515, 8322-8327. [CrossRef]

56. Mirzaei, A.; Leonardi, S.; Neri, G. Detection of hazardous volatile organic compounds (VOCs) by metal oxide nanostructuresbased gas sensors: A review. Ceram. Int. 2016, 42, 15119-15141. [CrossRef]

57. Ju, D.X.; Xu, H.Y.; Qiu, Z.W.; Zhang, Z.C.; Xu, Q.; Zhang, J.; Wang, J.Q.; Cao, B.Q. Near room temperature, fast-response, and highly sensitive triethylamine sensor assembled with Au-loaded $\mathrm{ZnO} / \mathrm{SnO}_{2}$ core-shell nanorods on flat alumina substrates. ACS Appl. Mater. Interfaces 2015, 7, 19163-19171. [CrossRef]

58. Mitsubayashi, K.; Kubotera, Y.; Yano, K.; Hashimoto, Y.; Kon, T.; Nakakura, S.; Nishi, Y.; Endo, H. Trimethylamine biosensor with flavin-containing monooxygenase type 3 (FMO3) for fish-freshness analysis. Sens. Actuators B Chem. 2004, 103, $463-467$. [CrossRef]

59. Li, W.; Xu, H.; Yu, H.; Zhai, T.; Xu, Q.; Yang, X.; Wang, J.; Cao, B. Different morphologies of ZnO and their triethylamine sensing properties. J. Alloy. Compd. 2017, 706, 461-469. [CrossRef]

60. Shen, Z.; Zhang, X.; Mi, R.; Liu, M.; Chen, Y.; Chen, C.; Ruan, S. On the high response towards TEA of gas sensors based on Ag-loaded 3D porous ZnO microspheres. Sens. Actuators B Chem. 2018, 270, 492-499. [CrossRef] 
61. Castro-Hurtado, I.; Mandayo, G.G.; Castaño, E. Conductometric formaldehyde gas sensors. A review: From conventional films to nanostructured materials. Thin Solid Film. 2013, 548, 665-676. [CrossRef]

62. Xiong, J.; Zhang, P.; Huang, S.; Zhang, Y. Comprehensive influence of environmental factors on the emission rate of formaldehyde and VOCs in building materials: Correlation development and exposure assessment. Environ. Res. 2016, 151, 734-741. [CrossRef]

63. Wang, J.; Yunus, R.; Li, J.; Li, P.; Zhang, P.; Kim, J. In situ synthesis of manganese oxides on polyester fiber for formaldehyde decomposition at room temperature. Appl. Surf. Sci. 2015, 357, 787-794. [CrossRef]

64. Dong, C.; Liu, X.; Han, B.; Deng, S.; Xiao, X.; Wang, Y. Nonaqueous synthesis of Ag-functionalized $\mathrm{In}_{2} \mathrm{O}_{3} / \mathrm{ZnO}$ nanocomposites for highly sensitive formaldehyde sensor. Sens. Actuators B Chem. 2016, 224, 193-200. [CrossRef]

65. Xing, X.; Xiao, X.; Wang, L.; Wang, Y. Highly sensitive formaldehyde gas sensor based on hierarchically porous Ag-loaded ZnO heterojunction nanocomposites. Sens. Actuators B Chem. 2017, 247, 797-806. [CrossRef]

66. Wang, S.; Xiao, B.; Yang, T.; Wang, P.; Xiao, C.; Li, Z.; Zhao, R.; Zhang, M. Enhanced HCHO gas sensing properties by Ag-loaded sunflower-like $\mathrm{In}_{2} \mathrm{O}_{3}$ hierarchical nanostructures. J. Mater. Chem. A 2014, 2, 6598-6604. [CrossRef]

67. Nakate, U.T.; Patil, P.; Na, S.-I.; Yu, Y.T.; Suh, E.-k.; Hahn, Y.-B. Fabrication and enhanced carbon monoxide gas sensing performance of $\mathrm{p}-\mathrm{CuO} / \mathrm{n}-\mathrm{TiO}_{2}$ heterojunction device. Colloids Surf. A Physicochem. Eng. 2020, 612, 125962. [CrossRef]

68. Niakan, H.; Zhang, C.; Hu, Y.; Szpunar, J.A.; Yang, Q. Thermal stability of diamond-like carbon-MoS 2 thin films in different environments. Thin Solid Film 2014, 562, 244-249. [CrossRef]

69. Zhang, D.; Sun, Y.E.; Jiang, C.; Yao, Y.; Wang, D.; Zhang, Y. Room-temperature highly sensitive CO gas sensor based on Ag-loaded zinc oxide/molybdenum disulfide ternary nanocomposite and its sensing properties. Sens. Actuators B Chem. 2017, 253, 1120-1128. [CrossRef]

70. Wang, Y.; Cui, Y.; Meng, X.; Zhang, Z.; Cao, J. A gas sensor based on Ag-modified ZnO flower-like microspheres: Temperaturemodulated dual selectivity to $\mathrm{CO}$ and $\mathrm{CH}_{4}$. Surf. Interfaces 2021, 24, 101110. [CrossRef]

71. Mirzaei, A.; Janghorban, K.; Hashemi, B.; Bonyani, M.; Leonardi, S.G.; Neri, G. Highly stable and selective ethanol sensor based on $\alpha-\mathrm{Fe}_{2} \mathrm{O}_{3}$ nanoparticles prepared by Pechini sol-gel method. Ceram. Inter. 2016, 42, 6136-6144. [CrossRef]

72. Tomer, V.K.; Malik, R.; Kailasam, K. Near-room-temperature ethanol detection using Ag-loaded mesoporous carbon nitrides. ACS Omega 2017, 2, 3658-3668. [CrossRef]

73. Zhang, Q.; Zang, P.; Hu, W.; Li, J.; Liu, Y.; Liu, Y.; Yu, F.; Zhang, C.; Xu, M. Performance degradation mechanism of the light-activated room temperature $\mathrm{NO}_{2}$ gas sensor based on Ag-ZnO nanoparticles. Appl. Surf. Sci. 2021, 541, 148418. [CrossRef]

74. Wang, Y.; Cui, X.; Yang, Q.; Liu, J.; Gao, Y.; Sun, P.; Lu, G. Preparation of Ag-loaded mesoporous $\mathrm{WO}_{3}$ and its enhanced $\mathrm{NO}_{2}$ sensing performance. Sens. Actuators B Chem. 2016, 225, 544-552. [CrossRef]

75. Espid, E.; Taghipour, F. Facile synthesis and UV-activated gas sensing performance of Ag: ZnO nano-ellipsoids. ECS J. Solid State Sci. Technol. 2018, 7, 3089. [CrossRef]

76. Zhang, Q.; Xie, G.; Xu, M.; Yu, S.; Tai, H.; Du, H.; Jiang, Y. Visible light-assisted room temperature gas sensing with ZnO-Ag heterostructure nanoparticles. Sens. Actuators B Chem. 2018, 259, 269-281. [CrossRef]

77. Garcia, D.; Picasso, G.; Hidalgo, P.; Peres, H.E.M.; Sun Kou, R.; Gonçalves, J.M. Sensors based on Ag-loaded hematite ( $\alpha$-Fe $\left.{ }_{2} \mathrm{O}_{3}\right)$ nanoparticles for methyl mercaptan detection at room temperature. Anal. Chem. Res. 2016, 12, 74-81. [CrossRef]

78. Mirzaei, A.; Kim, J.-H.; Kim, H.W.; Kim, S.S. Resistive-based gas sensors for detection of benzene, toluene and xylene (BTX) gases: A review. J. Mater. Chem. C 2018, 6, 4342-4370. [CrossRef]

79. Zheng, Y.; Wang, L.; Tian, H.; Qiao, L.; Zeng, Y.; Liu, C. Bimetal carbonaceous templates for multi-shelled $\mathrm{NiCo}_{2} \mathrm{O}_{4}$ hollow sphere with enhanced xylene detection. Sens. Actuators B Chem. 2021, 339, 129862. [CrossRef]

80. Zhang, Y.; Bai, J.; Zhou, L.; Du, L.; Liu, F.; Xiang, L.; Gao, Y.; Liu, F.; Yan, X.; Lu, G. Preparation of silver-loaded titanium dioxide hedgehog-like architecture composed of hundreds of nanorods and its fast response to xylene. J. Colloid Interface Sci. 2019, 536, 215-223. [CrossRef]

81. Kwak, D.; Lei, Y.; Maric, R. Ammonia gas sensors: A comprehensive review. Talanta 2019, 204, 713-730. [CrossRef]

82. Timmer, B.; Olthuis, W.; Aan, V.; Berg, D. Ammonia sensors and their applications-a review. Sens. Actuators B Chem. 2005, 107, 666-677. [CrossRef]

83. Karaduman, I.; Er, E.; Çelikkan, H.; Erk, N.; Acar, S. Room-temperature ammonia gas sensor based on reduced graphene oxide nanocomposites decorated by Ag, Au and Pt nanoparticles. J. Alloy. Compd. 2017, 722, 569-578. [CrossRef]

84. Qin, Y.; Zang, J.; Wen, Z. Synergistic functionalization of aligned silicon nanowires by Ag nanoparticles \& PPy wrapping for improving gas-sensing response at high humidity level. Phys. E Low-Dimens. Syst. Nanostructures 2020, $118,113957$.

85. Yoon, J.-W.; Hong, Y.J.; Chan Kang, Y.; Lee, J.-H. High performance chemiresistive $\mathrm{H}_{2} \mathrm{~S}$ sensors using Ag-loaded $\mathrm{SnO}_{2}$ yolk-shell nanostructures. RSC Adv. 2014, 4, 16067-16074. [CrossRef]

86. Uddin, A.S.M.I.; Lee, K.-W.; Chung, G.-S. Acetylene gas sensing properties of an Ag-loaded hierarchical ZnO nanostructuredecorated reduced graphene oxide hybrid. Sens. Actuators B Chem. 2015, 216, 33-40. [CrossRef]

87. Zhou, L.; Bai, J.; Liu, Y.; Liu, F.; Wang, H.; Zhang, Y.; Lu, G. Highly sensitive $\mathrm{C}_{2} \mathrm{H}_{2}$ gas sensor based on Ag modified ZnO nanorods. Ceram. Inter. 2020, 46, 15764-15771. [CrossRef]

88. Yousefi, H.R.; Hashemi, B.; Mirzaei, A.; Roshan, H.; Sheikhi, M.H. Effect of Ag on the ZnO nanoparticles properties as an ethanol vapor sensor. Mater. Sci. Semicond. Proc. 2020, 117, 105172. [CrossRef]

89. Nadargi, D.Y.; Bateer, D.R.; Tamboli, M.S.; Mulla, I.S.; Suryavanshi, S.S. A greener approach towards the development of graphene-Ag loaded $\mathrm{ZnO}$ nanocomposites for acetone sensing applications. RSC Adv. 2019, 9, 33602-33606. [CrossRef] 
90. Wang, H.; Li, Q.; Zheng, X.; Wang, C.; Ma, J.; Yan, B.; Du, Z.; Li, M.; Wang, W.; Fan, H. 3D porous flower-like ZnO microstructures loaded by large-size Ag and their ultrahigh sensitivity to ethanol. J. Alloy. Compd. 2020, 829, 154453. [CrossRef]

91. Xue, Y.-Y.; Wang, J.-L.; Li, S.-N.; Jiang, Y.-C.; Hu, M.-C.; Zhai, Q.-G. Mesoporous $\mathrm{Ag} / \mathrm{In}_{2} \mathrm{O}_{3}$ composite derived from indium organic framework as high performance formaldehyde sensor. J. Solid State Chem. 2017, 251, 170-175. [CrossRef]

92. Jiang, C.; Zhang, D.; Yin, N.; Yao, Y.; Shaymurat, T.; Zhou, X. Acetylene gas-sensing properties of layer-by-layer self-assembled Ag-decorated tin dioxide/graphene nanocomposite film. Nanomaterials 2017, 7, 278. [CrossRef] [PubMed]

93. Chen, M.; Zhang, D.; Hu, J.; Wang, H.; Zhang, Y.; Li, K.; Rong, Q.; Zhou, S.; Zhang, J.; Zhu, Z.; et al. Excellent toluene gas sensing properties of molecular imprinted $\mathrm{Ag}_{-} \mathrm{LaFeO}_{3}$ nanostructures synthesized by microwave-assisted process. Mater. Res. Bull. 2019, 111, 320-328. [CrossRef]

94. Liu, M.; Song, P.; Liang, D.; Yang, Z.; Wang, Q. Highly sensitive and selective triethylamine gas sensor based on Ag nanoparticlesdecorated $\mathrm{MoO}_{3}$ nanobelts. Mater. Res. Express 2019, 6, 125910. [CrossRef]

95. Liu, H.; Shen, W.; Chen, X. A room temperature operated ammonia gas sensor based on Ag-decorated $\mathrm{TiO}_{2}$ quantum dot clusters. RSC Adv. 2019, 9, 24519-24526. [CrossRef]

96. Kamble, C.; Panse, M.; Nimbalkar, A. Ag decorated $\mathrm{WO}_{3}$ sensor for the detection of sub-ppm level $\mathrm{NO}_{2}$ concentration in air. Mater. Sci. Semicond. Proc. 2019, 103, 104613. [CrossRef]

97. Ghanbari, R.; Safaiee, R.; Sheikhi, M.H.; Golshan, M.M.; Horastani, Z.K. Graphene decorated with silver nanoparticles as a low-temperature methane gas sensor. ACS Appl. Mater. Interfaces 2019, 11, 21795-21806. [CrossRef]

98. Liu, D.; Pan, J.; Tang, J.; Liu, W.; Bai, S.; Luo, R. Ag decorated $\mathrm{SnO}_{2}$ nanoparticles to enhance formaldehyde sensing properties. J. Phys. Chem. Solids 2019, 124, 36-43. [CrossRef]

99. Lin, Z.D.; Young, S.J.; Hsiao, C.H.; Chang, S.J. Adsorption sensitivity of Ag-decorated carbon nanotubes toward gas-phase compounds. Sens. Actuators B Chem. 2013, 188, 1230-1234. [CrossRef]

100. Li, Z.; Zhang, G.; Gao, W.; Zhao, R.; Wang, Y. Ag decorated ZnO nanocrystallines synthesized by a low-temperature solvothermal method and their application for high response $\mathrm{H}_{2}$ gas sensor. J. Mater. Sci. Mater. Electron. 2019, 30, 18959-18969.

101. Shim, Y.S.; Zhang, L.; Kim, Y.H.; Choi, Y.R.; Nahm, S.H.; Kang, C.Y.; Lee, W.; Jang, H.W. Highly sensitive and selective $\mathrm{H}_{2}$ and $\mathrm{NO}_{2}$ gas sensors based on surface-decorated $\mathrm{WO}_{3}$ nanoigloos. Sens. Actuators B Chem. 2014, 198, 294-301. [CrossRef]

102. Navaneethan, M.; Patil, V.L.; Ponnusamy, S.; Muthamizhchelvan, C.; Kawasaki, S.; Patil, P.S.; Hayakawa, Y. Sensitivity enhancement of ammonia gas sensor based on $\mathrm{Ag} / \mathrm{ZnO}$ flower and nanoellipsoids at low temperature. Sens. Actuators B Chem. 2018, 255, 672-683.

103. Yin, Y.; Li, F.; Zhang, N.; Ruan, S.; Zhang, H.; Chen, Y. Improved gas sensing properties of silver-functionalized $\mathrm{ZnSnO}_{3}$ hollow nanocubes. Inorg. Chem. Front. 2018, 5, 2123-2131. [CrossRef]

104. Choi, M.S.; Kim, M.Y.; Ahn, J.; Choi, S.J.; Lee, K.H. Ag-functionalized $\mathrm{SnO}_{2}$ nanowires-based sensor for $\mathrm{NO}_{2}$ detection at low operating temperature. J. Microelectron. Packag. Soc. 2020, 27, 11-17.

105. Park, S.; An, S.; Ko, H.; Jin, C.; Lee, C. Enhancement of ethanol sensing of $\mathrm{TeO}_{2}$ nanorods by Ag functionalization. Curr. Appl. Phys. 2013, 13, 576-580. [CrossRef]

106. Zhou, S.; Chen, M.; Lu, Q.; Zhang, Y.; Zhang, J.; Li, B.; Wei, H.; Hu, J.; Wang, H.; Liu, Q. Ag nanoparticles sensitized In ${ }_{2} \mathrm{O}_{3}$ nanograin for the ultrasensitive $\mathrm{HCHO}$ detection at room temperature. Nanoscale Res. Lett. 2019, 14, 1-11. [CrossRef]

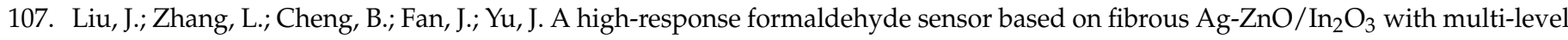
heterojunctions. J. Hazard. Mater. 2021, 413, 125352. [CrossRef] [PubMed]

108. Yu, H.; Li, J.; Li, Z.; Tian, Y.; Yang, Z. Enhanced formaldehyde sensing performance based on $\mathrm{Ag}_{3} \mathrm{WO}_{3} 2 \mathrm{D}$ nanocomposite. Powder Tech. 2019, 343, 1-10. [CrossRef]

109. Feng, D.L.; Zhu, Z.Y.; Du, L.L.; Xing, X.; Wang, C.; Chen, J.; Tian, Y.T.; Yang, D.C. Improved sensing performance of $\mathrm{WO}_{3}$ nanoparticles decorated with Ag and Pt nanoparticles. Rare Met. 2021, 40, 1642-1650. [CrossRef]

110. Degler, D.; Weimar, U.; Barsan, N. Current understanding of the fundamental mechanisms of doped and loaded semiconducting metal-oxide-based gas sensing materials. ACS Sens. 2019, 4, 2228-2249. [CrossRef]

111. Ristein, J. Surface transfer doping of semiconductors. Sci. N. Y. Wash. 2006, 313, 1057. [CrossRef]

112. Mirzaei, A.; Kim, S.S.; Kim, H.W. Resistance-based $\mathrm{H}_{2} \mathrm{~S}$ gas sensors using metal oxide nanostructures: A review of recent advances. J. Haz. Mater. 2018, 357, 314-331. [CrossRef]

113. Ovsianytskyi, O.; Nam, Y.-S.; Tsymbalenko, O.; Lan, P.-T.; Moon, M.-W.; Lee, K.-B. Highly sensitive chemiresistive $\mathrm{H}_{2} \mathrm{~S}$ gas sensor based on graphene decorated with Ag nanoparticles and charged impurities. Sens. Actuators B Chem. 2018, 257, 278. [CrossRef]

114. Kolhe, P.S.; Koinkar, P.M.; Maiti, N.; Sonawane, K.M. Synthesis of Ag doped $\mathrm{SnO}_{2}$ thin films for the evaluation of $\mathrm{H}_{2} \mathrm{~S}$ gas sensing properties. Phys. B Condens. Matter 2017, 524, 90-96. [CrossRef]

115. Anand, K.; Kaur, J.; Singh, R.C.; Thangaraj, R. Preparation and characterization of Ag-doped $\operatorname{In}_{2} \mathrm{O}_{3}$ nanoparticles gas sensor. Chem. Phys. Lett. 2017, 682, 140-146. [CrossRef]

116. Ding, M.; Xie, N.; Wang, C.; Kou, X.; Zhang, H.; Guo, L.; Sun, Y.; Chuai, X.; Gao, Y.; Liu, F.; et al. Enhanced $\mathrm{NO}_{2}$ gas sensing properties by Ag-doped hollow urchin-like $\mathrm{In}_{2} \mathrm{O}_{3}$ hierarchical nanostructures. Sens. Actuators B Chem. 2017, 252, 418-427. [CrossRef]

117. Al-Hadeethi, Y.; Umar, A.; Ibrahim, A.A.; Al-Heniti, S.H.; Kumar, R.; Baskoutas, S.; Raffah, B.M. Synthesis, characterization and acetone gas sensing applications of Ag-doped ZnO nanoneedles. Ceram. Inter. 2017, 43, 6765-6770. [CrossRef] 
118. Hong, C.; Zhou, Q.; Lu, Z.; Umar, A.; Kumar, R.; Wei, Z.; Wu, X.; Xu, L.; Kim, S.H. Ag-doped ZnO nanoellipsoids based highly sensitive gas sensor. Mater. Express 2017, 7, 380-388. [CrossRef]

119. Wei, W.; Guo, S.; Chen, C.; Sun, L.; Chen, Y.; Guo, W.; Ruan, S. High sensitive and fast formaldehyde gas sensor based on Ag-doped $\mathrm{LaFeO}_{3}$ nanofibers. J. Alloy. Compd. 2017, 695, 1122-1127. [CrossRef]

120. Wang, Y.; Wang, Y.; Cao, J.; Kong, F.; Xia, H.; Zhang, J.; Zhu, B.; Wang, S.; Wu, S. Low-temperature $\mathrm{H}_{2} \mathrm{~S}$ sensors based on Ag-doped $\alpha-\mathrm{Fe}_{2} \mathrm{O}_{3}$ nanoparticles. Sens. Actuators B Chem. 2008, 131, 183-189. [CrossRef]

121. Natkaeo, A.; Phokharatkul, D.; Hodak, J.H.; Wisitsoraat, A.; Hodak, S.K. Highly selective sub- 10 ppm $\mathrm{H}_{2} \mathrm{~S}$ gas sensors based on Ag-doped $\mathrm{CaCu}_{3} \mathrm{Ti}_{4} \mathrm{O}_{12}$ films. Sens. Actuators B Chem. 2018, 260, 571-580. [CrossRef]

122. Zhang, Y.; Zheng, Z.; Yang, F. Highly sensitive and selective alcohol sensors based on Ag-dped $\operatorname{In}_{2} \mathrm{O}_{3}$ Coating. Indus. Eng. Chem. Res. 2010, 49, 3539-3543. [CrossRef]

123. Zhang, R.; Ma, S.Y.; Zhang, Q.X.; Zhu, K.M.; Tie, Y.; Pei, S.T.; Wang, B.J.; Zhang, J.L. Highly sensitive formaldehyde gas sensors based on $\mathrm{Ag}$ doped $\mathrm{Zn}_{2} \mathrm{SnO}_{4} / \mathrm{SnO}_{2}$ hollow nanospheres. Mater. Lett. 2019, 254, 178-181. [CrossRef]

124. Lu, Z.; Zhou, Q.; Xu, L.; Gui, Y.; Zhao, Z.; Tang, C.; Chen, W. Synthesis and characterization of highly sensitive hydrogen $\left(\mathrm{H}_{2}\right)$ sensing device based on $\mathrm{Ag}$ doped $\mathrm{SnO}_{2}$ nanospheres. Materials 2018, 11, 492. [CrossRef] [PubMed]

125. Jeong, D.; Kim, K.; Park, S.-i.; Kim, Y.-h.; Kim, S.; Kim, S.-I. Characteristics of Ga and Ag-doped ZnO-based nanowires for an ethanol gas sensor prepared by hot-walled pulsed laser deposition. Res. Chem. Intermed. 2014, 40, 97-103. [CrossRef]

126. Wang, J.; Zou, B.; Ruan, S.; Zhao, J.; Chen, Q.; Wu, F. HCHO sensing properties of Ag-doped $\operatorname{In}_{2} \mathrm{O}_{3}$ nanofibers synthesized by electrospinning. Mater. Lett. 2009, 63, 1750-1753. [CrossRef]

127. Adilakshmi, G.; Reddy, R.S.; Reddy, A.S.; Reddy, P.S.; Reddy, C.S. Ag-doped $\mathrm{WO}_{3}$ nanostructure films for organic volatile gas sensor application. J. Mater. Sci. Mater. Electron. 2020, 31, 12158-12168. [CrossRef]

128. Postica, V.; Vahl, A.; Santos-Carballal, D.; Dankwort, T.; Kienle, L.; Hoppe, M.; Cadi-Essadek, A.; De Leeuw, N.H.; Terasa, M.I.; Adelung, R.; et al. Tuning $\mathrm{ZnO}$ sensors reactivity toward volatile organic compounds via Ag doping and nanoparticle functionalization. Acs Appl. Mater. Interfaces 2019, 11, 31452-31466. [CrossRef] [PubMed]

129. Abideen, Z.U.; Kim, J.-H.; Kim, S.S. Optimization of metal nanoparticle amount on $\mathrm{SnO}_{2}$ nanowires to achieve superior gas sensing properties. Sens. Actuators B Chem. 2016, 238, 374-380. [CrossRef]

130. Meng, F.; Zheng, H.; Sun, Y.; Li, M.; Liu, J. UV-activated room temperature single-sheet ZnO gas sensor. Micro Nano Lett. 2017, 12, 813-817. [CrossRef]

131. Fan, F.; Zhang, J.; Li, J.; Zhang, N.; Hong, R.; Deng, X.; Tang, P.; Li, D. Hydrogen sensing properties of Pt-Au bimetallic nanoparticles loaded on ZnO nanorods. Sens. Actuators B Chem. 2017, 241, 895-903. [CrossRef]

132. Mitri, F.; Iacovo, A.; Luca, M.; Pecora, A.; Colace, L. Lead sulphide colloidal quantum dots for room temperature $\mathrm{NO}_{2}$ gas sensors. Sci. Reports 2020, 10, 12556.

133. Wu, T.; Wang, Z.; Tian, M.; Miao, J.; Zhang, H.; Sun, J. UV excitation $\mathrm{NO}_{2}$ gas sensor sensitized by ZnO quantum dots at room temperature. Sens. Actuators B Chem. 2018, 259, 526-531. [CrossRef]

134. Ayhan, B.; Kwan, C.; Zhou, J.; Kish, L.B.; Benkstein, K.D.; Rogers, P.H.; Semancik, S. Fluctuation enhanced sensing (FES) with a nanostructured, semiconducting metal oxide film for gas detection and classification. Sens. Actuators B Chem. 2013, 188, 651-660. [CrossRef]

135. Kish, L.B.; Smulko, J.; Heszler, P.; Granqvist, C.G. On the sensitivity, selectivity, sensory information and optimal size of resistive chemical sensors. Nanotechnol. Percept. 2007, 3, 43-52. [CrossRef]

136. Ederth, J.; Smulko, J.M.; Kish, L.B.; Heszler, P.; Granqvist, C.G. Comparison of classical and fluctuation-enhanced gas sensing with $\mathrm{PdxWO}_{3}$ nanoparticle films. Sens. Actuators B Chem. 2006, 113, 310-315. [CrossRef]

137. Kish, L.B.; Vajtai, R.; Granqvist, C.G. Extracting information from the noise spectra of chemical sensors: Electronic nose and tongue by one sensor. Sens. Actuators B Chem. 2000, 71, 55-59. [CrossRef] 